\title{
Modeling Analysis of Primary Controls on Net Ecosystem Productivity of Seven Boreal and Temperate Coniferous Forests Across a Continental Transect
}

\section{Citation}

Yuan, Fengming, M. Altaf Arain, Alan G. Barr, T. Andrew Black, Charles P.A. Bourque, Carole Coursolle, Hank A. Margolis, J. Harry McCaughey, and Steven C. Wofsy. 2008. Modeling analysis of primary controls on net ecosystem productivity of seven boreal and temperate coniferous forests across a continental transect. Global Change Biology 14, no. 8: 1765-1784.

\section{Published Version}

http://dx.doi.org/10.1111/j.1365-2486.2008.01612.x

\section{Permanent link}

http://nrs.harvard.edu/urn-3:HUL.InstRepos:3342971

\section{Terms of Use}

This article was downloaded from Harvard University's DASH repository, and is made available under the terms and conditions applicable to Other Posted Material, as set forth at http:// nrs.harvard.edu/urn-3:HUL.InstRepos:dash.current.terms-of-use\#LAA

\section{Share Your Story}

The Harvard community has made this article openly available.

Please share how this access benefits you. Submit a story. 


\title{
Modeling analysis of primary controls on net ecosystem productivity of seven boreal and temperate coniferous forests across a continental transect
}

\author{
FENGMING YUAN*1, M. ALTAFARAIN*, ALAN G. BARR†, T. ANDREW BLACK‡, \\ CHARLES P.-A. BOURQUE§, CAROLE COURSOLLEף, HANKA. MARGOLIS , \\ J. HARRY MCCAUGHEY $\|$ and STEVEN C. WOFSY** \\ *School of Geography and Earth Sciences, McMaster University, Hamilton, ON, Canada, †Climate Research Division, Environment \\ Canada, Saskatoon, SK, Canada, †Biometeorology and Soil Physics Group, Faculty of Land and Food Systems, University of British \\ Columbia, Vancouver, BC, Canada, §Faculty of Forestry and Environmental Management, University of New Brunswick, \\ Fredericton, NB, Canada, $\mid$ Faculté de Foresterie et de Géomatique, Université Laval, Quebec City, QC, Canada, \|Department of \\ Geography, Queen's University, Kingston, ON, Canada, ${ }^{* *}$ Department of Earth and Planetary Science, Harvard University, \\ Cambridge, MA, USA
}

\begin{abstract}
Process-based models are effective tools to synthesize and/or extrapolate measured carbon (C) exchanges from individual sites to large scales. In this study, we used a $\mathrm{C}$ - and nitrogen (N)-cycle coupled ecosystem model named CN-CLASS (Carbon NitrogenCanadian Land Surface Scheme) to study the role of primary climatic controls and sitespecific $C$ stocks on the net ecosystem productivity (NEP) of seven intermediate-aged to mature coniferous forest sites across an east-west continental transect in Canada. The model was parameterized using a common set of parameters, except for two used in empirical canopy conductance-assimilation, and leaf area-sapwood relationships, and then validated using observed eddy covariance flux data. Leaf Rubisco-N dynamics that are associated with soil-plant $\mathrm{N}$ cycling, and depend on canopy temperature, enabled the model to simulate site-specific gross ecosystem productivity (GEP) reasonably well for all seven sites. Overall GEP simulations had relatively smaller differences compared with observations vs. ecosystem respiration (RE), which was the sum of many plant and soil components with larger variability and/or uncertainty associated with them. Both observed and simulated data showed that, on an annual basis, boreal forest sites were either carbon-neutral or a weak $\mathrm{C}$ sink, ranging from 30 to $180 \mathrm{~g} \mathrm{C} \mathrm{m}^{-2} \mathrm{yr}^{-1}$; while temperate forests were either a medium or strong $C$ sink, ranging from 150 to $500 \mathrm{~g} \mathrm{C} \mathrm{m}^{-2} \mathrm{yr}^{-1}$, depending on forest age and climatic regime. Model sensitivity tests illustrated that air temperature, among climate variables, and aboveground biomass, among major $C$ stocks, were dominant factors impacting annual NEP. Vegetation biomass effects on annual GEP, RE and NEP showed similar patterns of variability at four boreal and three temperate forests. Air temperature showed different impacts on GEP and RE, and the response varied considerably from site to site. Higher solar radiation enhanced GEP, while precipitation differences had a minor effect. Magnitude of forest litter content and soil organic matter (SOM) affected RE. SOM also affected GEP, but only at low levels of SOM, because of low $\mathrm{N}$ mineralization that limited soil nutrient $(\mathrm{N})$ availability. The results of this study will help to evaluate the impact of future climatic changes and/or forest $C$ stock variations on $C$ uptake and loss in forest ecosystems growing in diverse environments.
\end{abstract}

\footnotetext{
Correspondence: M. Altaf Arain, tel. + 19055259140 ext. 27941,

fax + 1905546 0463, e-mail: arainm@mcmaster.ca

${ }^{1}$ Present address: Department of Hydrology and Water Resources, the University of Arizona, Tucson, AZ 85721, USA. 
Keywords: boreal forests, Canadian land surface scheme, carbon cycle, ecosystem model, net ecosystem productivity, temperate forests

Received 10 July 2007; revised version received 14 January 2008 and accepted 1 February 2008

\section{Introduction}

Eddy covariance flux data from tower networks (e.g. AmeriFlux, EuroFlux, AsiaFlux and Fluxnet-Canada, presently known as the Canadian Carbon Program) are now available for a number of sites worldwide, monitoring the dynamics of major terrestrial ecosystems (Aubinet et al., 2000; Baldocchi et al., 2001; Gu \& Baldocchi, 2002; Margolis et al., 2006; Yu et al., 2006). However, the integration and synthesis of these sitespecific flux data to regional, continental and global scales is challenging. Such synthesis exercises are crucial to obtain magnitude and uncertainty estimates in terrestrial ecosystem carbon $(C)$ budgets and to identify the primary controlling factors, as well as their roles in defining ecosystem dynamics (Gu \& Baldocchi, 2002; Medlyn et al., 2005a; Raupach et al., 2005; Dolman et al., 2006; Friend et al., 2007).

Terrestrial ecosystem models are valuable tools for this purpose. Eddy covariance flux data have been used to evaluate, validate and calibrate a number of ecosystem models, particularly those applied to forest ecosystems (e.g. Arain et al., 2002; Kramer et al., 2002; Papale \& Valentini, 2003; Falge et al., 2005; Grant et al., 2005, 2006; Medlyn et al., 2005a, b; Morales et al., 2005; Arain et al., 2006; Kucharik et al., 2006; Friend et al., 2007; Piao et al., 2008). Except for a few 'black box' models (e.g. artificial neural network models, such as described in Melesse \& Hanley, 2005), most of these models are process-based with different levels of detail. Generally, these models are parameterized using site-specific information to fit with observations, and, as a result, their application beyond the reference ecosystem often leads to poor simulations. For example, Medlyn et al. (2005a) parameterized the MAESTRA model for three EuroFlux coniferous forests with contrasting parameter values for leaf photosynthesis and ecosystem respiration (RE; in their Table 1). Similarly, various model inter-comparison studies have shown that even for the same site, various models used different values of the same parameters to simulate ecosystem processes relevant to carbon dioxide $\left(\mathrm{CO}_{2}\right)$ and water vapor fluxes (e.g. Grant et al., 2005, 2006). These site-specific model parameters may be compared and/or classified into certain categories depending on biome type, age, climate or geographical regions, etc., to conduct regional and/or perhaps global C cycle modeling studies. Alternatively, because of the continuing accumulation of flux data from multiple sites across the world and the development of coupling of physical, physiological, biogeochemical and other relevant processes in terrestrial ecosystem models, it may be possible to generalize process-based model parameters at larger scales. This would challenge model parameterization and development, but use of a common set of model parameters for key processes for multiple sites would help to assess the ability of the model to simulate correctly seasonal and annual $\mathrm{C}$ cycles in diverse climatic regions and to identify sources of errors for conducting these simulations at larger spatial scales.

A process-based terrestrial ecosystem model, Carbon (C)- and nitrogen (N)-cycle coupled Canadian Land Surface Scheme (CN-CLASS; Arain et al., 2006; Yuan et al., 2007) was developed and validated using multiyear (1998-2002) observed $\mathrm{CO}_{2}$ flux data from a temperate forest in BC, Canada. In this study, CN-CLASS is being used to examine the $\mathrm{C}$ balance of seven coniferous forest ecosystems, by minimizing site-specific model parameters to simulate their net ecosystem productivity (NEP). The sites are geographically distributed along an east-west transect from the Atlantic region to the Pacific coast in Canada and represent diverse climatic conditions in the Canadian boreal and temperate regions. The sites are being studied under the Fluxnet-Canada Research Network (FCRN) or presently the Canadian Carbon Program (CCP) (Coursolle et al., 2006; Margolis et al., 2006). The primary objective of this study was to analyze the role of key environmental controls (i.e. solar radiation, air temperature and precipitation) and site $\mathrm{C}$ stocks (i.e. above- and belowground biomass and forest floor litter) on $\mathrm{C}$ cycling in a range of forest ecosystems across a continental transect and to determine the impact of future variations in climate and forest $C$ stocks on NEP of these sites located in diverse environments. The secondary objective of this study was to search for ways in which process-based $\mathrm{C}$ exchange model parameters may be simplified to simulate $\mathrm{CO}_{2}$ exchanges at large spatial scales in forest ecosystems.

\section{Materials and methods}

\section{Study sites}

The FCRN has six main and two associated forest flux stations along a continental transect stretching from the east coast to the west coast in southern Canada 
(Margolis et al., 2006). Each forest station contains a cluster of flux towers having a minimum of one tower in a mature or intermediate-aged forest, where $\mathrm{CO}_{2}$ fluxes are measured year-round, using the eddy covariance technique. Of these continuous flux tower sites, seven are dominated by evergreen coniferous tree species, namely (from east to west): (1) a newly established balsam-fir forest site in the central New Brunswick (NBBF67; Xing et al., 2005), (2) an old black spruce forest $(\sim 120$ years old) in the eastern boreal region in Quebec (QC-EOBS; Bergeron et al., 2007), (3) a white pine stand planted in 1939 in southern Ontario (ON-WPP39; Arain \& Restrepo-Coupe, 2005; Peichl \& Arain, 2006), (4) an old black spruce forest in the northern boreal region of Manitoba (MB-NOBS; Harden et al., 1997; Grant et al., 2001; Dunn et al., 2007), (6) a 90-year-old jack pine forest in the southern boreal region in Saskatchewan (SK-OJP), which is part of the Boreal Ecosystem Research and Monitoring Sites (BERMS) project (Baldocchi \& Vogel, 1996; Baldocchi et al., 1997; Sellers et al., 1997; Griffis et al., 2003), (6) a naturally occurring 110 -year-old black spruce forest in the southern boreal region in Saskatchewan (SK-SOBS), also a part of BERMS (Jarvis et al., 1997; Arain et al., 2002) and (7) a Douglas-fir stand planted in 1949 on Vancouver Island, British Columbia (BC-DF49; Morgenstern et al., 2004; Humphreys et al., 2006). These forests are located in five major terrestrial eco-zones in southern Canada (i.e. Atlantic Maritime, Mixedwood Plains, Boreal Shield, Boreal Plains, Pacific Maritime; Coursolle et al., 2006) and can be grouped into two general categories: boreal forests and temperate forests. The site characteristics including soil, vegetation and climate are given in Tables 1 and 2. Overall the soil textures are coarse. The four boreal sites are oldgrowth forests, while the three temperate forests are younger and planted. There are large differences in $\mathrm{C}$ stocks among the sites. Generally, forests located in the temperate region receive more solar radiation and precipitation than boreal forests, and are exposed to warmer and wetter weather conditions. All of these favor faster growth, but may suppress accumulation of soil organic matter because of increased decomposition rates as compared with litter production.

\section{Site meteorology and measured fluxes}

This study used continuously observed meteorological and $\mathrm{CO}_{2}$ flux data from October 1, 2003 to September 30, 2004 for model simulations and comparisons. This study period had near normal air temperature at all sites when compared with long-term normals (Table 2). The precipitation was near normal at the two temperate forests and one boreal site (BC-DF49, ON-WPP39 and QC-EOBS) and below normal at NB-BF67. Compared with climate normals, precipitation was greater at the two southern boreal forests (SK-OJP and SK-SOBS) and lower at the northern (MB-NOBS).

The above-canopy $\mathrm{CO}_{2}$ fluxes $\left(F_{\mathrm{c}}\right)$ were measured using the eddy covariance technique. NEP was calculated by taking the negative value of the sum of $F_{\mathrm{c}}$ and the rate of change in $\mathrm{CO}_{2}$ storage $\left(F_{\mathrm{s}}\right.$ or $\left.\mathrm{d} S_{\mathrm{c}} / \mathrm{dt}\right)$ in the air column below the eddy covariance sensors. Observed flux data coverage was $95 \%, 82 \%$ and $58 \%$ for BC-DF49, ON-WPP39 and NB-BF67, respectively, at the temperate sites, while at the boreal sites flux data coverage was $80 \%, 84 \%, 70 \%$ and $68 \%$ at SK-OJP, SKSOBS, MB-NOBS and QC-EOBS, respectively. The halfhourly raw NEP data were first filtered by removing erroneous values and night-time data during low turbulence hours using site-specific friction velocity $\left(u^{*}\right)$ threshold values. For the temperate sites, observed flux data coverage after removal of erroneous and lowfriction velocity data was $59 \%, 59 \%$ and $34 \%$ for BC-DF49, ON-WPP39 and NB-BF67, respectively, while at the boreal sites filtered flux data coverage was $46 \%$, $50 \%, 46 \%$ and $45 \%$ at SK-OJP, SK-SOBS, MB-NOBS and QC-EOBS, respectively. Large gaps at NB-BF67 site were mostly caused by exclusion of $\mathrm{CO}_{2}$ flux data collected during the winter season by an open-path eddy covariance system, using a LI-COR Li-7500 IRGA (Lincoln, NE, USA). Overall, data coverage was similar to those reported by Falge et al. (2001) at other flux tower sites.

In order to integrate $\mathrm{C}$ exchanges over daily, monthly and yearly interval, these data gaps were filled following the procedure described in Barr et al. (2004). Gross ecosystem productivity (GEP) and RE were also calculated following Barr et al. (2004). Data processing and gap-filling steps were to (1) calculate RE for periods when photosynthesis was zero, i.e. night-time and the winter when soil temperature at $2-5 \mathrm{~cm}$ depths was below $0{ }^{\circ} \mathrm{C}$, (2) determine a relationship between $\mathrm{RE}$ and soil temperature $\left(T_{\mathrm{s}}\right)$ at either 2 or $5 \mathrm{~cm}$, (3) fill night-time missing and daytime RE values, using a 'moving window' approach, (4) calculate half-hourly GEP as the sum of observed NEP and fitted RE during the daytime, (5) fit the relationship between GEP and photosynthetically active radiation $\left(Q_{\mathrm{i}}\right)$, (6) adjust the estimated GEP by a 'moving window' approach, and use it to fill missing GEP values and (7) calculate missing NEP as the difference between adjusted and fitted GEP and $R E$ values. The same gap-filling procedure was used for all sites, except for BC-DF49, where the gap-filling procedure was similar, but no 'moving window' was used, as described by Morgenstern et al. (2004).

Gap filling introduces uncertainty in measured fluxes, which has been described in detail by Morgenstern et al. (2004) and Falge et al. (2001). Baldocchi et al. 


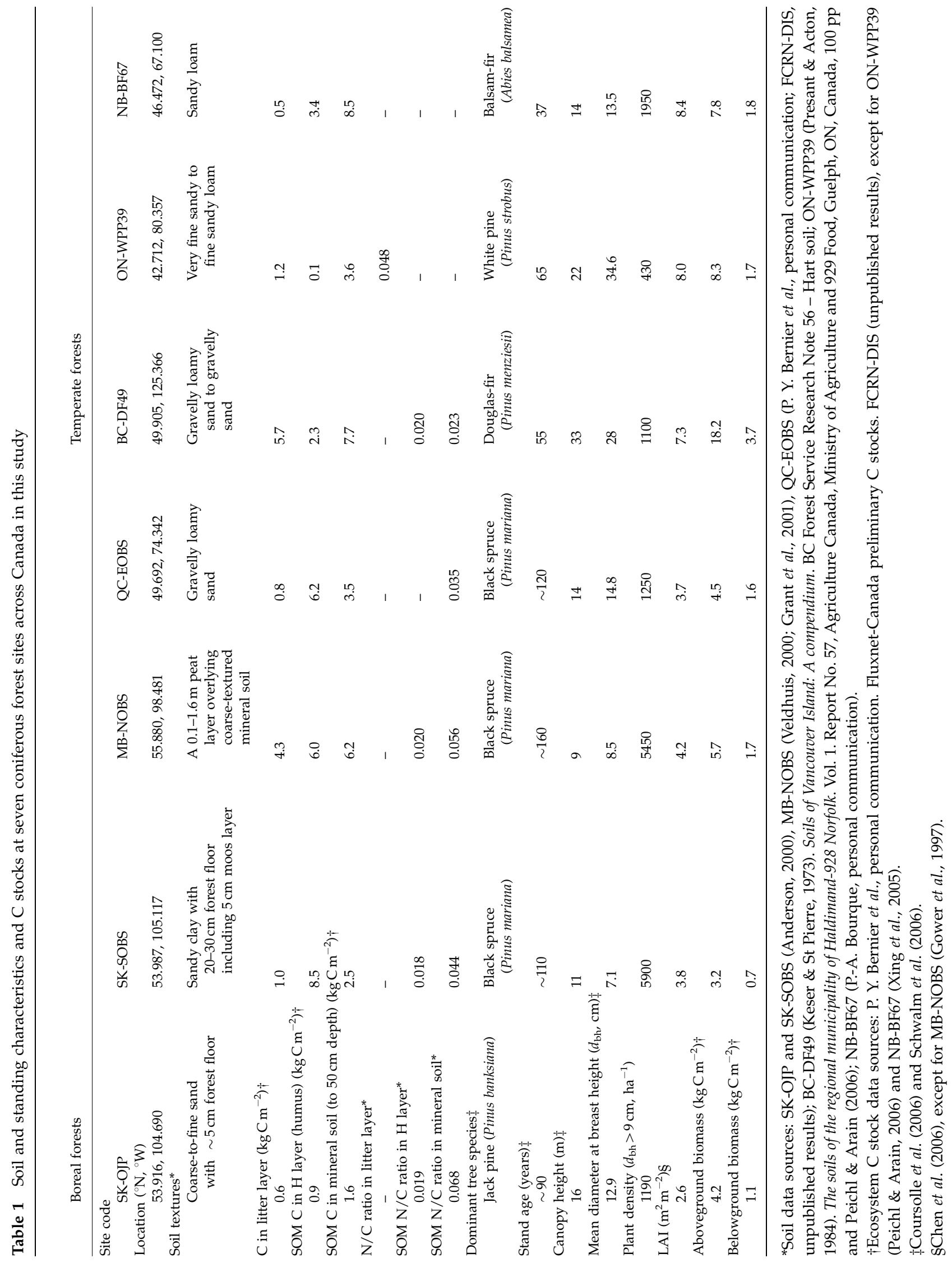


Table 2 Normal air temperature and precipitation, and summary of climate conditions from October 1, 2003 to September 30, 2004 at seven coniferous forest sites across Canada

\begin{tabular}{|c|c|c|c|c|c|c|}
\hline \multicolumn{2}{|l|}{ Boreal forests } & & & \multicolumn{3}{|c|}{ Temperate forests } \\
\hline \multicolumn{7}{|l|}{ Site code } \\
\hline SK-OJP & SK-SOBS & MB-NOBS & QC-EOBS & BC-DF49 & ON-WPP39 & NB-BF67 \\
\hline \multicolumn{7}{|l|}{ Location $\left({ }^{\circ} \mathrm{N},{ }^{\circ} \mathrm{W}\right)$} \\
\hline $53.916,104.690$ & $53.987,105.117$ & $55.880,98.481$ & $49.692,74.342$ & $49.905,125.366$ & $42.712,80.357$ & $46.472,67.100$ \\
\hline \multicolumn{7}{|c|}{ Normal annual mean air temperature $\left({ }^{\circ} \mathrm{C}\right)$} \\
\hline 0.4 & 0.4 & -3.2 & 0.0 & 8.3 & 7.8 & 2.1 \\
\hline \multicolumn{7}{|c|}{ Normal annual precipitation (mm) } \\
\hline 467 & 467 & 517 & 961 & 1461 & 1010 & 1196 \\
\hline \multicolumn{7}{|c|}{ Total incident solar radiation $\left(\mathrm{MJ} \mathrm{m}^{-2}\right)$ during the study period } \\
\hline 4061 & 4080 & 3240 & 3832 & 4151 & 4883 & 4570 \\
\hline \multicolumn{7}{|c|}{ Total precipitation $(\mathrm{mm})$ during the study period } \\
\hline 681 & 880 & 306 & 1042 & 1276 & 1122 & 857 \\
\hline \multicolumn{7}{|c|}{ Mean air temperature $\left({ }^{\circ} \mathrm{C}\right)$ during the study period } \\
\hline 0.58 & 0.04 & -1.43 & 0.09 & 8.47 & 7.84 & 3.55 \\
\hline \multicolumn{7}{|c|}{ Mean specific humidity $\left(\mathrm{kg} \mathrm{kg}^{-1}\right)$ during the study period } \\
\hline 0.00362 & 0.00359 & 0.00355 & 0.00394 & 0.00592 & 0.00666 & 0.00456 \\
\hline
\end{tabular}

(2001) described that current levels of eddy covariance flux data acceptance provided a statistically robust estimate of the ensemble means. Therefore, the filling of missing data does not provide a significant source of bias error in measured eddy covariance flux data. In this study, we regard daily, monthly and annual gapfilled eddy covariance flux data as 'observed' or 'measured' flux data.

\section{Model overview and simulations}

CLASS was developed initially to provide the Canadian General Circulation Model (CGCM) and Regional Climate Model with land-surface process detail and forcing functions (Verseghy, 1991; Verseghy et al., 1993). CLASS has been further augmented with the incorporation of photosynthesis and respiration algorithms for $\mathrm{C}_{3}$ and $\mathrm{C}_{4}$ plants, yielding C-CLASS (Wang et al., 2001; Arain et al., 2002) and the subsequent incorporation of a dynamic vegetation model, the Canadian Terrestrial Ecosystems Model (CTEM; Arora \& Boer, 2005). Recently CLASS was upgraded by incorporating modules addressing coupled $\mathrm{C}$ and $\mathrm{N}$ cycles into the latest CLASS version 3 (CN-CLASS; Arain et al., 2006; Yuan et al., 2007). In this study, to accommodate all the seven forest sites, which have a wide range of tree sizes and plant densities, a simple tree allometry module with dynamic leaf phenology was developed and incorporated in the CN-CLASS. The module calculates leaf area index (LAI) and other forest $C$ components from input or model-updated values of plant density, aboveground biomass, litter $\mathrm{C}$ and total soil organic matter (SOM). LAI calculations are based on allometric relationships considering aboveground biomass and plant density (given in Table 1). Leaf surface area per unit biomass, known as specific leaf area (SLA), is used to convert leaf biomass to LAI and was set to $7.5 \mathrm{~m}^{2} \mathrm{~kg}^{-1}$ biomass for all the seven sites. Further model details are given in the 'Appendix' and can also be found in Arain et al. (2006) and Yuan et al. (2007).

In contrast to previous modeling studies using earlier versions of CLASS, where soil layer depths were fixed at 10,25 and $375 \mathrm{~cm}$, the soil layers, in this study were variable and prescribed according to the LFH, A and lower mineral horizons (down to $410 \mathrm{~cm}$ ) obtained from soil surveys at each site. Maximum root zone depth was set to $1.0 \mathrm{~m}$ for all sites, so that trees could extract water stored in soils down to $1.0 \mathrm{~m}$ depth. The model was driven using measured half-hourly downwelling shortwave and long-wave radiation, air temperature, specific humidity, precipitation and atmospheric pressure.

Initial C stocks for aboveground biomass, belowground (root) biomass, litter and SOM are prescribed from observed data (Table 1). Other initial conditions such as fine root biomass, short-lived SOM, canopy temperature, soil temperature and soil moisture were set arbitrarily. The model was spun-up for 10 years, using the same forcing data repetitively and resetting the aboveground biomass, litter and total $\mathrm{C}$ content in SOM each year to their observed values to stabilize above-mentioned initial variables before starting formal simulations on October 1, 2003. A set of constant C/N ratios for the ecosystem $\mathrm{C}$ stocks was used at all sites, because of unavailability of the necessary input data, especially for vegetation (Table 1). This limitation would not affect results of this study, because it focuses 
on seasonal $\mathrm{C}$ changes for which effects of $\mathrm{N}$ cycling may not be significant because it operated at longer time scales in forest ecosystems.

Observed and simulated half-hourly, daily, monthly and annual GEP, RE and NEP values were compared, to evaluate the model performance in simulating seasonal dynamics and annual $C$ balance at each site. The degree of agreement between observed and simulated fluxes was assessed by calculating the coefficients of determination $\left(R^{2}\right)$, mean error (ME) and root mean square error (RMSE).

\section{Sensitivity analysis}

In order to assess the relative influences of climatic variables and $C$ stocks on $C$ exchanges among sites or within a site, model sensitivity tests were conducted at each site. For climatic variables, the sensitivity was evaluated by increasing/decreasing half-hourly values of (1) incident solar radiation by $\pm 5 \%$ and $\pm 10 \%$, (2) air temperature by \pm 0.5 and $\pm 1.0{ }^{\circ} \mathrm{C}$, or (3) precipitation by $\pm 10 \%$ and $\pm 20 \%$ of observed values, respectively. One variable was changed at a time, while all others were kept unchanged, during this exercise. Similar sensitivity analysis was performed for aboveground biomass (including both stem and leaf biomass), litter, or SOM, which are considered as three major C stocks in forest ecosystems, by increasing/decreasing their initial values by $\pm 20 \%$ and $\pm 50 \%$. Changes in the aboveground biomass affected modeled LAI and belowground biomass as well, as discussed later.

\section{Results}

\section{Model parameterization}

Model parameterization was conducted using halfhourly measured (nongap-filled) NEP values. This exercise helped to (1) reduce errors between simulated and measured data at all sites and (2) minimize number of site-specific parameters used for all the seven study sites. A list of key parameters used to run the model at all seven sites is given in Table 3 . This modeling exercise demonstrated that only two parameters had significant differences among sites; one controlling the empirical canopy conductance relationship [Eqn (A4)] and the other defining the LAI relationship with sapwood crosssectional area [Eqn (A6)]. However, it was possible to use a single set of photosynthesis parameters to simulate half-hourly NEP values, with acceptable accuracy limits (as shown later), at all seven forest sites growing in different environments. Analysis of the initial model testing results revealed that at least three groups of parameters appeared to be crucial for successful simulation of C uptakes (photosynthesis) at all seven forests, i.e. (1) the maximum carboxylation rate of Rubisco in leaves, $V_{\text {cmax }}$ and the potential rate of wholechain electron transport, $J_{\max }$, (2) temperature criteria for $V_{\text {cmax }}$ and $J_{\max }$ and (3) empirical parameters controlling the relationship between the canopy conductance for $\mathrm{CO}_{2}, \mathrm{G}_{\mathrm{c}}$ and net $\mathrm{CO}_{2}$ fixation, $A_{\text {net }}$ [Eqn (A4)].

In the model, $V_{\text {cmax }}$ and $J_{\max }$ varied both temporally and spatially. They are closely associated with soilplant $\mathrm{N}$ cycling and canopy thermal conditions related to energy (heat) exchanges between air and vegetation. Specifically, the $V_{\text {cmax }}$ (and thus $J_{\max }$ ) is modulated by the differences in leaf Rubisco- $\mathrm{N}$ content among sites and its activity determined by canopy temperature. Table 4 summarizes simulated $V_{\text {cmax }}$ and Rubisco-N concentration values in the upper canopy for all the seven forests. For individual sites, $V_{\text {cmax }}$ had higher seasonal variation (coefficient of variation, CV, of 59$162 \%$ ) than Rubisco-N concentration values (CV of $2-7 \%$ ). Therefore, canopy temperature controlled most of the seasonal variation in Rubisco activity in individual forests. However, the CV of the Rubisco-N concentration among sites was 28\%, $14 \%$ and $24 \%$ for boreal, temperate and all the seven sites, respectively. Hence, we conclude that site-specific soil-plant $\mathrm{N}$ cycling characteristics were more important in modulating photosynthesis than seasonal dynamics of soil-plant $\mathrm{N}$ status.

The model runs for determining parameter values further demonstrated that the different temperature criteria (minimum, optimum and maximum), for $V_{\text {cmax }}$ and $J_{\text {max }}$, had only a small effect in boreal forests, but could affect the simulation of GEP in winter seasons in temperate sites, where the $\mathrm{C}$ uptake during the relatively mild and wet winters could not be ignored, as described later. Lower minimum and optimum temperatures for $J_{\max }$ compared with $V_{\text {cmax }}$ (Table 3) allowed the model to simulate winter $\mathrm{CO}_{2}$ uptakes in temperate forests.

In CN-CLASS, the relationship of $A_{\text {net }}$ with $G_{\mathrm{c}}$ was defined by a semimechanistic model [modified BallWoodrow-Berry equation, Eqn (A4)]. Because $G_{c}$ was closely associated with transpiration, this relationship governed water use efficiency, which varied depending on stand-age, species type and composition, and/or site environments (Medlyn et al., 2005a; Coursolle et al., 2006). $G_{c}$ was most sensitive to two empirical constants, $D_{0}$ and $a_{1}$. To simplify the analysis, we held $D_{0}$ constant and varied $a_{1}$ only by site (see Table 3 ). In doing so, the parameter $a_{1}$ lost the original physical meaning as proposed in the Ball-Woodrow-Berry equation. We observed that this parameter was pretty similar for the four old boreal forests (values ranging from 2.3 to 2.5), but varied among the three temperate forests (i.e. 5.0 for BC-DF49, 2.5 for ON-WPP39 and 3.5 for NB-BF67; 
Table 3 Key parameters for all seven coniferous forests across Canada used to run the CN-CLASS model

\begin{tabular}{|c|c|c|}
\hline \multicolumn{2}{|l|}{ Parameters* } & \multirow{2}{*}{$\begin{array}{l}\text { Values } \\
302.0 \times 10^{-6} \mathrm{~mol} \mathrm{~mol}^{-1}\end{array}$} \\
\hline $\begin{array}{l}\text { Michelis-Menten } \\
\text { coefficient for } \mathrm{CO}_{2}\end{array}$ & $K_{\mathrm{c}}$ & \\
\hline $\begin{array}{l}\text { Michelis-Menten } \\
\text { coefficient for } \mathrm{O}_{2}\end{array}$ & $K_{\mathrm{o}}$ & $256.0 \times 10^{-6} \mathrm{~mol} \mathrm{~mol}^{-1}$ \\
\hline $\begin{array}{l}\text { Empirical constant } \\
\text { for } \mathrm{CO}_{2} \\
\text { compensation point }\end{array}$ & $\gamma_{0}$ & $\begin{array}{l}28.0 \times 10^{-6} \mathrm{~mol} \mathrm{~mol}^{-1} \text { at } \\
25^{\circ} \mathrm{C}\end{array}$ \\
\hline $\begin{array}{l}\text { Empirical constant } \\
\text { for } \mathrm{CO}_{2} \\
\text { compensation point }\end{array}$ & $\gamma_{1}$ & 0.0451 \\
\hline $\begin{array}{l}\text { Empirical constant } \\
\text { for } \mathrm{CO}_{2} \\
\text { compensation point }\end{array}$ & $\gamma_{2}$ & 0.000347 \\
\hline $\begin{array}{l}\text { Parameter in } J-Q \\
\text { nonrectangular } \\
\text { equation }\end{array}$ & $A$ & 0.2 \\
\hline $\begin{array}{l}\text { Quantum efficiency } \\
\text { of RuBP } \\
\text { regeneration }\end{array}$ & $B$ & $0.2 \mathrm{~mol} \mathrm{~mol}^{-1}$ quanta \\
\hline $\begin{array}{l}\text { Maximum value of } \\
V_{\mathrm{cmax}}\end{array}$ & $A$ & $150 \mu \mathrm{mol} \mathrm{m}^{-2} \mathrm{~s}^{-1}$ \\
\hline $\begin{array}{l}\text { Minimum, } \\
\text { optimum and } \\
\text { maximum leaf } \\
\text { temperature for } \\
V_{\mathrm{cmax}}\end{array}$ & $\begin{array}{l}T_{\min } \\
T_{\text {opt }} \\
T_{\max }\end{array}$ & $0,35,45^{\circ} \mathrm{C}$ \\
\hline $\begin{array}{l}\text { Minimum, } \\
\text { optimum and } \\
\text { maximum leaf } \\
\text { temperature for } \\
J_{\max }\end{array}$ & $\begin{array}{l}T_{\min } \\
T_{\text {opt }} \\
T_{\max }\end{array}$ & $-5,30,45^{\circ} \mathrm{C}$ \\
\hline $\begin{array}{l}\text { Constant related to } \\
\text { inter-cellular } \mathrm{CO}_{2} \\
\text { concentration }\end{array}$ & $a_{1}$ & $\begin{array}{l}\text { SK-OJP: } 2.5 \\
\text { SK-SOBS: } 2.3 \\
\text { MB-NOBS: } 2.5 \\
\text { QC-EOBS: } 2.5 \\
\text { BC-DF49: } 5.0 \\
\text { ON-WPP39: } 2.5 \\
\text { NB-BF67: } 3.5\end{array}$ \\
\hline $\begin{array}{l}\text { Empirical } \\
\text { parameter for } \\
\text { stomatal sensitivity } \\
\text { to VPD }\end{array}$ & $D_{0}$ & $1500 \mathrm{~Pa}$ \\
\hline $\begin{array}{l}\text { Minimum canopy } \\
\text { conductance }\end{array}$ & $G_{\mathrm{c} 0}$ & $0.001 \mathrm{~mol} \mathrm{~m}^{-2} \mathrm{~s}^{-1}$ \\
\hline $\begin{array}{l}\text { Maintenance } \\
\text { respiration rates at } \\
\text { reference condition: }\end{array}$ & $R_{\text {ref }}$ & \\
\hline (1) Leaf & & $0.3 \mu \mathrm{mol} \mathrm{m}^{-2} \mathrm{~s}^{-1}\left(15^{\circ} \mathrm{C}\right)$ \\
\hline $\begin{array}{l}\text { (2) Living wood } \\
\text { (sapwood) }\end{array}$ & & $2.3 \mu \mathrm{mol} \mathrm{m}{ }^{-3} \mathrm{~s}^{-1}\left(15^{\circ} \mathrm{C}\right)$ \\
\hline (3) Fine root & & $2.0 \mu \mathrm{mol} \mathrm{kg}{ }^{-1} \mathrm{C} \mathrm{s}^{-1}\left(15^{\circ} \mathrm{C}\right)$ \\
\hline (4) Coarse root & & $0.2 \mu \mathrm{mol} \mathrm{kg}{ }^{-1} \mathrm{C} \mathrm{s}^{-1}\left(15^{\circ} \mathrm{C}\right)$ \\
\hline & $R_{\mathrm{s} 0}$ & \\
\hline
\end{tabular}

Table 3. (Contd.)

\begin{tabular}{|c|c|c|}
\hline \multicolumn{2}{|l|}{ Parameters* } & Values \\
\hline \multicolumn{3}{|l|}{$\begin{array}{l}\text { Base heterotrophic } \\
\text { respiration rates } \\
\text { at reference } \\
\text { conditions: }\end{array}$} \\
\hline (1) Litter & & $5.0 \mu \mathrm{mol} \mathrm{kg}{ }^{-1} \mathrm{C} \mathrm{s}^{-1}\left(15^{\circ} \mathrm{C}\right)$ \\
\hline (2) Short-lived SOM & & $10.0 \mu \mathrm{mol} \mathrm{kg}{ }^{-1} \mathrm{C} \mathrm{s}^{-1}\left(15^{\circ} \mathrm{C}\right)$ \\
\hline (3) Stable SOM & & $0.15 \mu \mathrm{mol} \mathrm{kg}{ }^{-1} \mathrm{C} \mathrm{s}^{-1}\left(15^{\circ} \mathrm{C}\right)$ \\
\hline $\begin{array}{l}\text { Ratio of leaf area } \\
\text { index to cross- } \\
\text { sectional area of } \\
\text { sapwood at BH }\end{array}$ & $l_{a}$ & $\begin{array}{l}\text { Four boreal forests: } 0.35 \\
\text { BC-DF49: } 0.30 \\
\text { ON-WPP39 and NB-BF67: } \\
0.50\end{array}$ \\
\hline $\begin{array}{l}\text { Empirical constants } \\
\text { of } d_{\mathrm{bh}} \text {-stem } \\
\text { biomass } \\
\text { relationship }\end{array}$ & $a_{\mathrm{w}}, b_{\mathrm{w}}$ & $-1.13,2.31$ \\
\hline $\begin{array}{l}\text { Empirical constants } \\
\text { of sapwood } \\
\text { volume- } d_{\mathrm{bh}} \\
\text { relationship }\end{array}$ & $\begin{array}{l}a_{\mathrm{s}}, b_{\mathrm{s}} \\
c_{\mathrm{s}}\end{array}$ & $-4.15,2.39,0.0$ \\
\hline $\begin{array}{l}\text { Empirical constants } \\
\text { of coarse root } \\
\text { biomass- } d_{\mathrm{bh}} \\
\text { relationship }\end{array}$ & $a_{\mathrm{r}}, b_{\mathrm{r}}$ & $6.56,2.20$ \\
\hline
\end{tabular}

*Details are referred to Arain et al. (2006) and the description in context.

Table 4 Mean and standard deviation (SD) of CN-CLASS modeled top canopy Rubisco-N content (Nrub0, leaf area based) and maximum Rubisco activity $\left(V_{\mathrm{cmax} 0}\right)$ from October 1, 2003 to September 30, 2004 at seven coniferous forest sites across Canada

\begin{tabular}{lll}
\hline & $\begin{array}{l}V_{\mathrm{cmax0}}\left(\mu \mathrm{mol} \mathrm{m}^{-2} \mathrm{~s}^{-1}\right) \\
(\operatorname{mean} \pm \mathrm{SD})\end{array}$ & $\begin{array}{l}\left.\text { Nrub0 }(\mathrm{gN} \mathrm{m})^{-2}\right) \\
(\mathrm{mean} \pm \mathrm{SD})\end{array}$ \\
\hline SK-OJP & $6.8 \pm 10.7$ & $0.377 \pm 0.027$ \\
SK-SOBS & $8.9 \pm 14.4$ & $0.598 \pm 0.011$ \\
MB-NOBS & $9.3 \pm 15.1$ & $0.549 \pm 0.013$ \\
QC-EOBS & $7.2 \pm 11.3$ & $0.448 \pm 0.026$ \\
Four boreal & $8.5 \pm 14.0$ & $0.548 \pm 0.152$ \\
$\quad$ forests & & $0.724 \pm 0.029$ \\
BC-DF49 & $26.8 \pm 15.9$ & $0.540 \pm 0.018$ \\
ON-WPP39 & $15.5 \pm 18.9$ & $0.725 \pm 0.042$ \\
NB-BF67 & $12.6 \pm 18.1$ & $0.663 \pm 0.092$ \\
Three & $18.3 \pm 18.7$ & \\
temperate & & $0.597 \pm 0.142$ \\
forests & &
\end{tabular}

Table 3). Lower values of $a_{1}$ may be related to diminishing water use efficiency in older forests, because all four boreal stands were older, and ON-WPP39 was also the oldest among the three temperate forest sites. 
LAI values are crucial to accurately simulate both photosynthesis and leaf respiration at each site. We adapted the empirical tree allometric functions from Gower et al. (1997), Turner et al. (2000) and Litton et al. (2003) [see Eqns (A5)-(A11) and Table 3] to describe forest structure. Assuming 85\% of total aboveground biomass $C$ is in the stems (Peichl \& Arain, 2006), the simulated diameter at breast height, $d_{\mathrm{bh}}$ values were about $13.4 \mathrm{~cm}$ (SK-OJP), $6.0 \mathrm{~cm}$ (SK-SOBS), $7.9 \mathrm{~cm}$ (MBNOBS) and $13.5 \mathrm{~cm}$ (QC-EOBS) for the boreal forests and $28.6 \mathrm{~cm}$ (BC-DF49), $27.6 \mathrm{~cm}$ (ON-WPP39) and $12.8 \mathrm{~cm}$ (NB-BF67) for the temperate forests. These functions were able to approximate the observed $d_{\mathrm{bh}}$ (see Table 1) at each site. The ratio of maximum LAI to sapwood area at breast height $\left[l_{\mathrm{a}}\right.$ in Eqn (A6) and Table 3$]$ was 0.35 for the boreal forests and 0.50 for the temperate forests, except for the 55-year-old Douglas-fir forest, for which it was 0.30 . With these modifications, simulated LAI values were, on an average, 3.1 (SK-OJP), 3.4 (SK-SOBS), 5.4 (MB-NOBS), 3.3 (QC-EOBS), 7.2 (BC-DF49), 5.4 (ON-WPP39) and 8.4 (NB-BF67), with seasonal variation of $0.3-1.0$ during the study period. These LAI values were very close to the observations, except for a large difference at ON-WPP39 site, where white pine needles were highly clumped with an observed LAI value of 8.0 without full crown closure (Table 1 and Chen et al., 2006).

\section{Simulated vs. measured half-hourly $\mathrm{CO}_{2}$ exchange}

Comparison of simulated and observed nongap-filled half-hourly NEP values at all the seven forest sites is

(a)

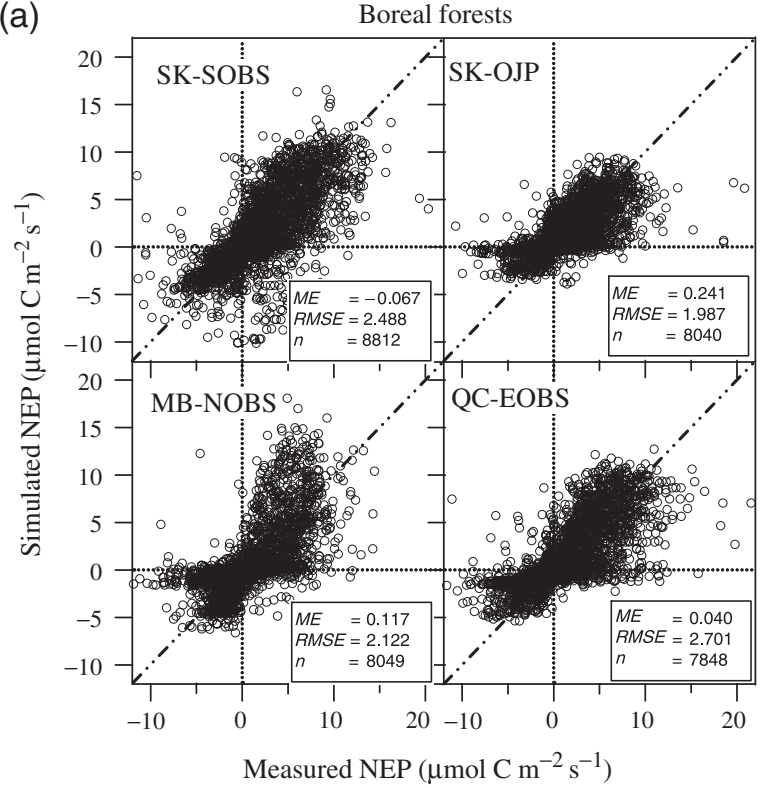

shown in Fig. 1. The model was able to simulate halfhourly NEP values at all the study sites within acceptable accuracy limits. For the boreal sites, the RMSE between simulated and observed NEP values were 2.49, 1.98, 2.12 and $2.70 \mu \mathrm{mol} \mathrm{C} \mathrm{m}^{-2} \mathrm{~s}^{-1}$ for SK-SOBS, SK-OJP, MB-NOBS and QC-EOBS, respectively (Fig. 1a). RMSE values were higher at the three temperate forests with 5.54, 3.84 and $4.35 \mu \mathrm{mol} \mathrm{C} \mathrm{m}^{-2} \mathrm{~s}^{-1}$ at BC-DF49, ON-WPP39 and NB-BF67, respectively (Fig. 1b). The model slightly overestimated NEP at the two boreal sites (SK-OJP and MB-NOBS), while it underestimated NEP at the two temperate forest sites (BC-DF49 and NB-BF67), as indicated by the ME values. When both, boreal and temperate, forest data were pooled together, RMSE values of half-hourly NEP were $2.45,4.87$ and $3.74 \mu \mathrm{mol} \mathrm{C} \mathrm{m}{ }^{-2} \mathrm{~s}^{-1}$, respectively, for boreal, temperate and all the seven sites combined. Temperate forests had larger ecosystem $C$ uptake and loss values compared with boreal forests, so larger absolute RMSE values did not imply larger simulation errors.

\section{Simulated vs. measured daily $\mathrm{CO}_{2}$ exchanges}

When we integrated model results into daily values, the model still performed very well, as judged by the overall small ME and RMSE values between simulated and observed variables. Note that daily observed values were gap-filled for missing data and/or night-time NEP values, when turbulence was low, as described earlier. The ME values were nearly zero when pooling both, boreal and temperate, forest data together. The RMSE (b)

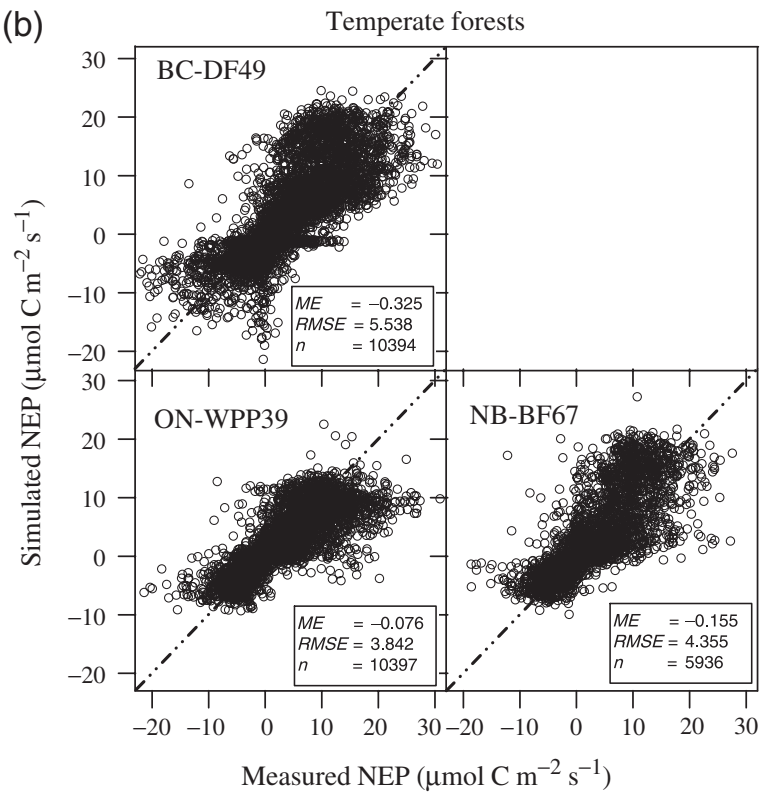

Fig. 1 Comparison of CN-CLASS simulated and eddy covariance measured half-hourly NEP (nongap-filled) at all the seven conifer forest sites across Canada. 
values between simulated and observed GEP, RE and NEP were 1.01, 0.89 and $0.78 \mathrm{~g} \mathrm{C} \mathrm{m}^{-2}$ day $^{-1}$ for boreal sites, as compared with $1.91,1.32$ and $1.62 \mathrm{~g} \mathrm{C} \mathrm{m}^{-2}$ day $^{-1}$ for temperate sites. Among the four boreal forest sites, the simulated daily GEP, RE and NEP values were better at SK-SOBS than the other sites, although both GEP and RE were overestimated. Daily NEP was slightly overestimated (positive ME) at SK-OJP and QC-EOBS, due to the underestimation of RE. Similarly, the slight underestimation of daily NEP values at the MB-NOBS was the result of a larger overestimation of RE than GEP. For the three temperate forests, GEP, RE and NEP were better simulated at ON-WPP39 than the other two temperate sites, as implied by relatively smaller RMSE values for GEP, RE and NEP, although both GEP and RE were underestimated by the model. The underestimation of daily NEP at BC-DF49 was a result of GEP underestimation, while at NB-BF67 it was a result of higher simulated $R E$ values. Overall, the model showed larger bias in daily GEP at one boreal site (MB-NOBS) and one temperate site (BC-DF49). The coefficient of determination $\left(R^{2}\right)$ between simulated and observed GEP was $0.82-0.87$ for the boreal forests and $0.80-0.87$ for the temperate forests. The simulation bias in daily RE had similar ranges for all the seven forest sites $\left(R^{2}=0.75-0.92\right.$ for the boreal sites and $0.79-0.91$ for the temperate sites). Overall, errors in modeled daily NEP were greater than for GEP, as indicated by much lower $R^{2}$ values (0.34-0.47 at the boreal sites and $0.43-0.50$ at the temperate sites).

\section{Seasonal trends in $C$ exchanges}

In the boreal forests, both observations and simulations showed that significant photosynthetic activity started in April, peaked in July and August (GEP of about $150 \mathrm{gC} \mathrm{m}^{-2}$ month $^{-1}$; average of both months) and almost ceased by the end of October (Fig. 2a). All four boreal sites had similar seasonal patterns for RE as for GEP, with peak values occurring either in July or in August (Figs 2a and 3a). But the time course of monthly values showed a small lag between peak GEP and RE values for each site. This occurred because (1) RE responds less sensitively than GEP to spring warming and (2) soil temperature, which controls the heterotrophic component of RE, lags air temperature and radiation, which controls GEP. The time-series mismatch between the seasonal cycles of GEP and RE in the boreal forests resulted in maximum net $\mathrm{C}$ uptake (NEP, $40-60 \mathrm{~g} \mathrm{C} \mathrm{m}^{-2} \mathrm{month}^{-1}$ ) in June (Fig. 4a), just before the peak photosynthetic activity. In July, the RE values increased closer to GEP, resulting in reduced NEP. In August, the decline in RE again produced positive monthly NEP, except for MB-NOBS site, at which the RE peak occurred later than at other sites (Figs $3 a$ and $4 a$ ).

Similar C uptake and release trends were also observed at the three temperate forest sites. The temperate forests started to photosynthesize 1-2 months earlier than the boreal forests (i.e. in February at BC-DF49 and in March at ON-WPP39 and NB-BF67 sites; Fig. 2b). Their net $C$ uptake period lasted until October, with the highest monthly NEP in the spring or early summer, followed by a depression to near zero NEP during July and August, similar to boreal forests (Fig. 4b). At three temperate forests, particularly BC-DF49 and NB-BF67, small values of GEP were observed even during winter, because the temperature often remained above freezing (Fig. 2b). The peak monthly GEP at the temperate sites ranged from about 250 to $375 \mathrm{~g} \mathrm{C} \mathrm{m}^{-2} \mathrm{month}^{-1}$ in either July and/or August. While RE in temperate forests still increased gradually until July and/or August (Fig. 3b), the seasonal NEP values reached the maximum (about $50-100 \mathrm{~g} \mathrm{C} \mathrm{m}^{-2} \mathrm{month}^{-1}$ ) in April/May at BC-DF49, in June at ON-WPP39 and in May at NB-BF67 (Fig. 4b), because $\mathrm{RE}$ reached a maximum later on in temperate forests.

CN-CLASS was able to simulate the time course of monthly GEP very well, with the largest biases at the two temperate forests (BC-DF49 and NB-BF67; Fig. 2). During the tree growth period from June/July to September/October, the model overestimated RE at two boreal (SK-SOBS and MB-NOBS) and two temperate forests (ON-WPP39 and NB-BF67; Fig. 3). The $R^{2}$ between simulated and observed monthly fluxes was slightly higher for GEP ( 0.96 boreal and 0.95 temperate sites) than RE (0.92 boreal and 0.93 temperate sites). In particular, the model underestimated RE at SK-OJP and BC-DF49 from July to September and at QC-EOBS site from June to July (Fig. 3). These large biases in simulated RE during the growing season were not associated with biases in GEP, except at the MB-NOBS site. The bias in RE resulted in a large underestimation of NEP at SK-SOBS, ON-WPP39 and NB-BF67 sites and an overestimation at SK-OJP, QC-EOBS and BC-DF49 (Fig. 4). During winter seasons, CN-CLASS simulated lower NEP than observed at the two temperate sites (BC-DF49 and NB-BF67) mainly due to large underestimation of GEP (Figs $2 b$ and $4 b$ ), but overestimated NEP at ON-WPP39 site due to a slight underestimation of RE (Figs $3 b$ and $4 b$ ). As for the four boreal forests in winter seasons, the simulations were not biased from observations, which could be real because of cold weather preventing any significant biological activity, or unknown because of lack of reliable eddy covariance measurements from November to March (nongap-filled flux data coverage was less than one-third, with January being the worst month as shown in Figs 2-4). 
(a)

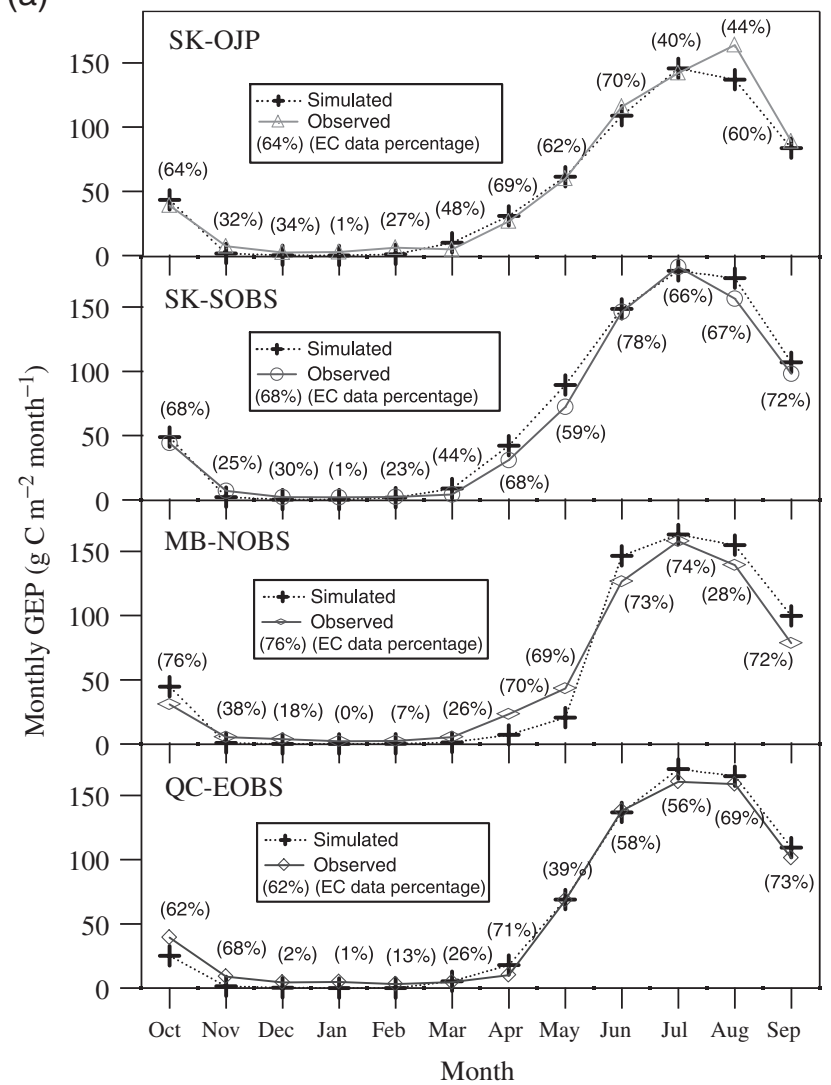

(b)

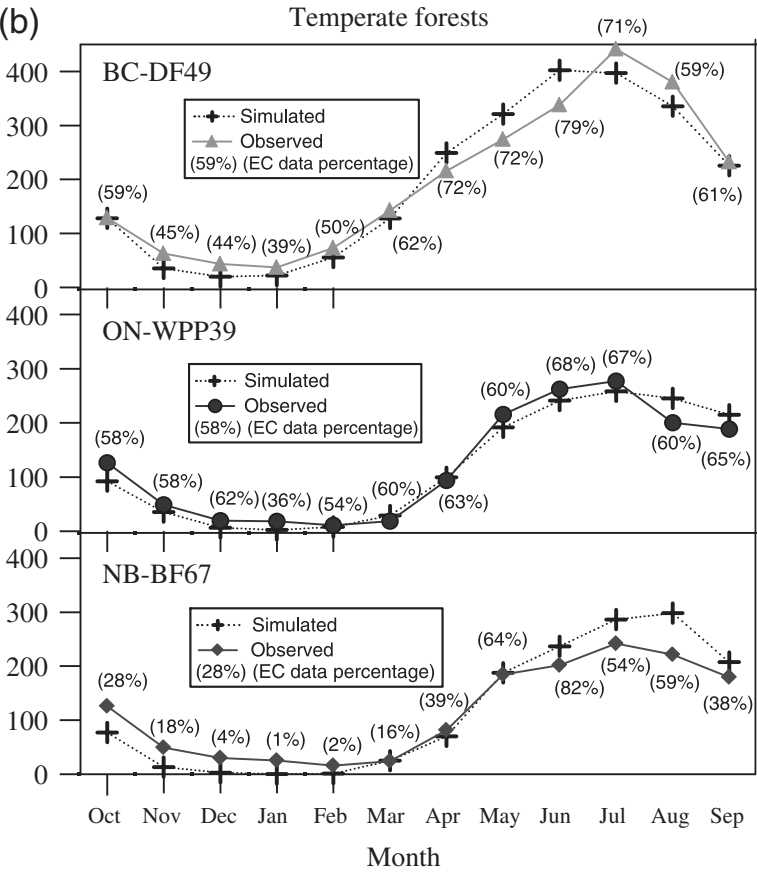

Fig. 2 Comparison of CN-CLASS simulated and measured (gap-filled) monthly GEP at all the seven conifer forest sites across Canada. Note that the percentage of nongap-filled measured data is shown for each month.

\section{Annual $C$ exchanges}

Comparison of eddy covariance technique based on observed annual estimates of GEP and RE with simulated values showed better agreement for GEP than for RE for the boreal forest sites, except at MB-NOBS (Table 5). At the boreal sites, GEP was slightly overestimated, with observed annual GEP ranging from 616 to $745 \mathrm{~g} \mathrm{C} \mathrm{m}^{-2}$, while simulated GEP ranged from 658 to $800 \mathrm{~g} \mathrm{C} \mathrm{m}^{-2}$. In contrast, $\mathrm{RE}$ was overestimated at some sites and underestimated at others, with observed annual RE values ranging from 535 to $673 \mathrm{~g} \mathrm{C} \mathrm{m}^{-2}$, compared with simulated $\mathrm{RE}$ values of $438-742 \mathrm{~g} \mathrm{C} \mathrm{m}^{-2}$. The slight mismatch between simulated and observed GEP and RE values did not alter the overall conclusions of this study. Both observed and simulated NEP values showed that boreal forests were carbon neutral or weak carbon sinks, with simulated annual NEP values ranging from 33 to $187 \mathrm{~g} \mathrm{C} \mathrm{m}^{-2}$, compared with observed NEP values of 36 to $104 \mathrm{~g} \mathrm{C} \mathrm{m}^{-2}$, if taking into account the gap-filling errors of about $5-53 \mathrm{~g} \mathrm{C} \mathrm{m}^{-2}$ for OBS sites (Griffis et al., 2003; Bergeron et al.,
2007) and up to $90 \mathrm{gCm}^{-2}$ for SOJP (Griffis et al., 2003).

Temperate forests had much higher GEP and RE than the boreal stands (Table 5), due to younger stand ages and more favorable site conditions (Tables 1 and 2). Simulated annual GEP, RE and NEP at the rotation-age BC-DF49 site, with its mild winters, were 2368, 2095 and $273 \mathrm{~g} \mathrm{C} \mathrm{m}^{-2}$, respectively. In contrast, annual GEP, RE and NEP were 1380,871 and $508 \mathrm{~g} \mathrm{C} \mathrm{m}^{-2}$ at the much younger maritime balsam-fir forest (NB-BF67) and 1477, 1315 and $162 \mathrm{~g} \mathrm{C} \mathrm{m}^{-2}$ at the 67 -year-old white pine forest in southern Ontario (ON-WPP39), with its cool continental climate (see Table 5 for side-by-side comparison). Although GEP values for ON-WPP39 and NB-BF67 were comparable, the higher RE values (about $1400 \mathrm{~g} \mathrm{C} \mathrm{m}^{-2}$ ) for ON-WPP39 resulted in considerably lower annual NEP compared with NB-BF67 (Table 5). According to the estimation by Morgenstern et al. (2004), the uncertainty of annual NEP by gap-filling errors, based on eddy covariance measurements at BC-DF49 site, was about $\pm 30 \mathrm{~g} \mathrm{C} \mathrm{m}^{-2}$, therefore overall CN-CLASS simulated the annual NEP very well. 
(a)

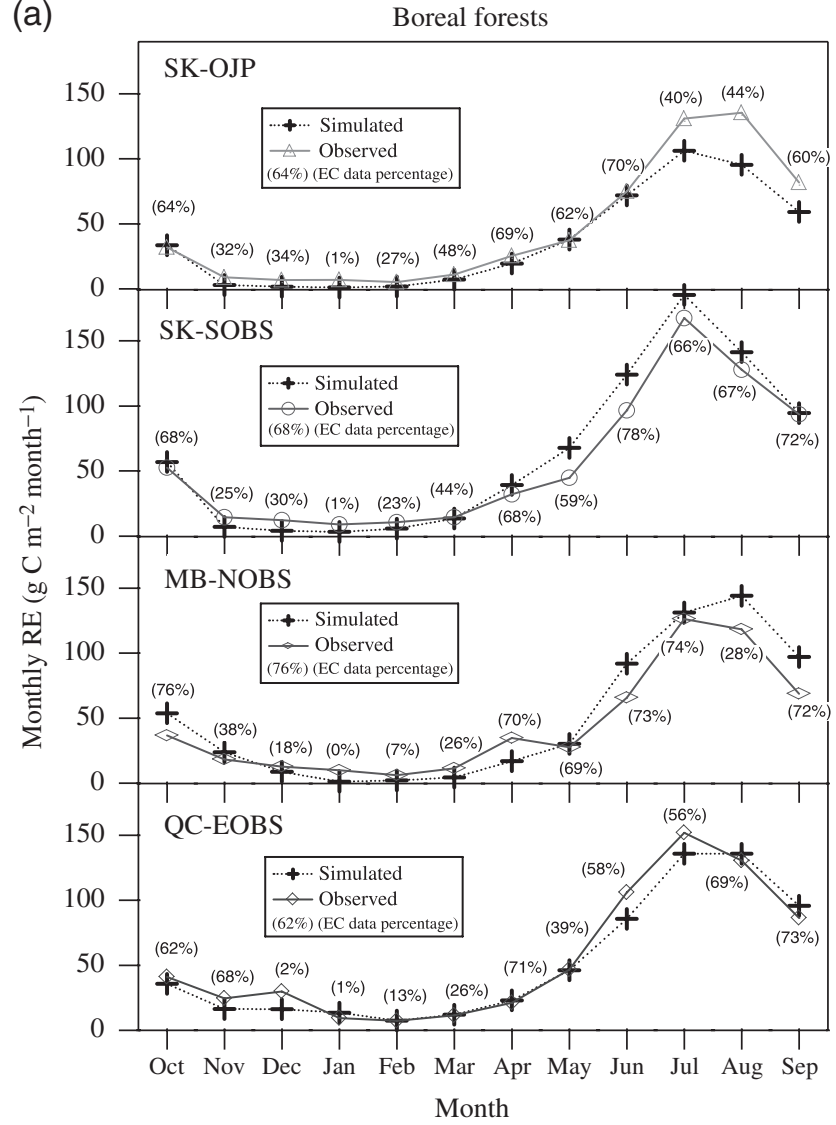

(b) Temperate forests

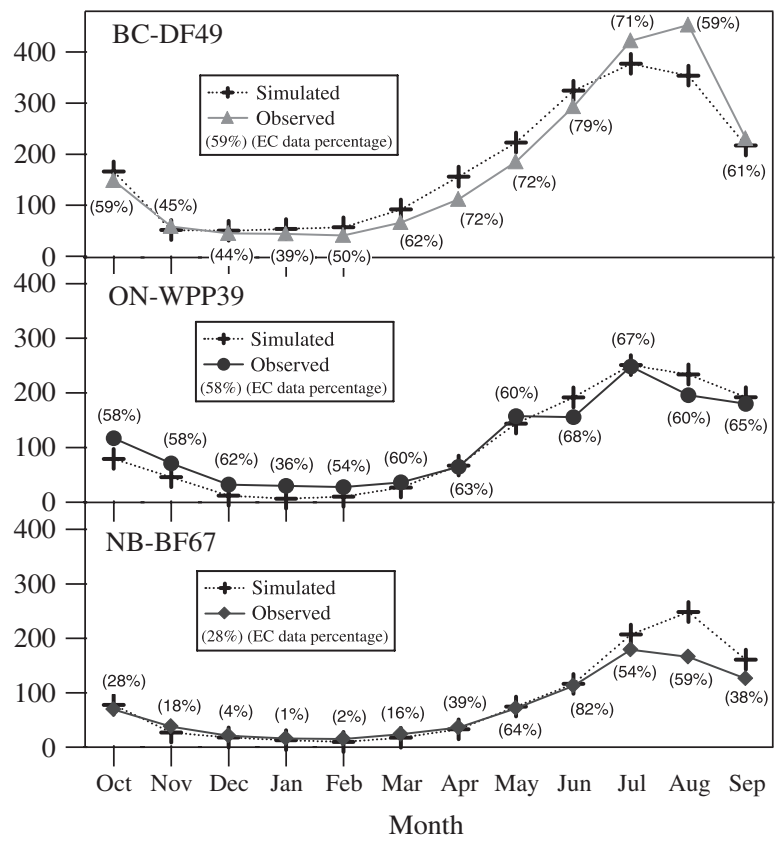

Fig. 3 Comparison of CN-CLASS simulated and measured (gap-filled) monthly RE at all the seven conifer forest sites across Canada. Note that the percentage of nongap-filled measured data is shown for each month.

\section{Sensitivity of climatic controls on $C$ exchange}

In the boreal region, annual total solar radiation, mean air temperature and total precipitation were lower than in the temperate region (Table 2). The differences in GEP, RE and NEP in boreal and temperate regions, therefore, could imply a positive, but nonlinear correlation between annual $C$ exchanges and climatic variables among the study sites (Fig. 5). Because of the compounding effects of climatic forcing on $\mathrm{C}$ exchange, we used model sensitivity analyses to isolate the critical climatic controls, varying one factor at a time.

When data for all the seven sites were pooled together, a positive relationship between $C$ exchanges and downwelling solar radiation was observed at boreal and temperate forests (Fig. 5a). This implies that solar radiation is a limiting factor for GEP, RE and NEP at each forest. The slopes of the GEP vs. solar radiation relationship were larger than those of RE vs. solar radiation (Fig. 5 b), baecause higher solar radiation affected GEP directly, but RE indirectly through higher autotrophic (growth) respiration, as well as heterotrophic respiration due to increase in litter/soil temperatures. Increasing the site-specific solar radiation by $5 \%$ and $10 \%$ at each site resulted in a nearly linear increase of simulated annual GEP, RE and NEP values (Fig. 5a-c). The response of intermediateaged temperate forests to increase in solar radiation was greater than the older boreal forests. However, the small positive response in sensitivity curves indicated that radiation limitation alone played a relatively small role in $\mathrm{C}$ exchanges in these well-established forests.

Unlike solar radiation, air temperature had opposite impact on annual GEP and RE (Fig. 5d-e). Generally, increase in air temperature promoted higher RE, while only slightly enhancing GEP. However, these responses varied greatly from site to site. For example, there was almost no response (positive or negative) of GEP to temperature change at ON-WPP39 (Fig. 5d). Overall, the contrasting responses of $\mathrm{C}$ uptake and release to site-specific temperature variations resulted in decrease in annual NEP with increasing air temperature (Fig. 5f). However, the apparent trends among the sites were 

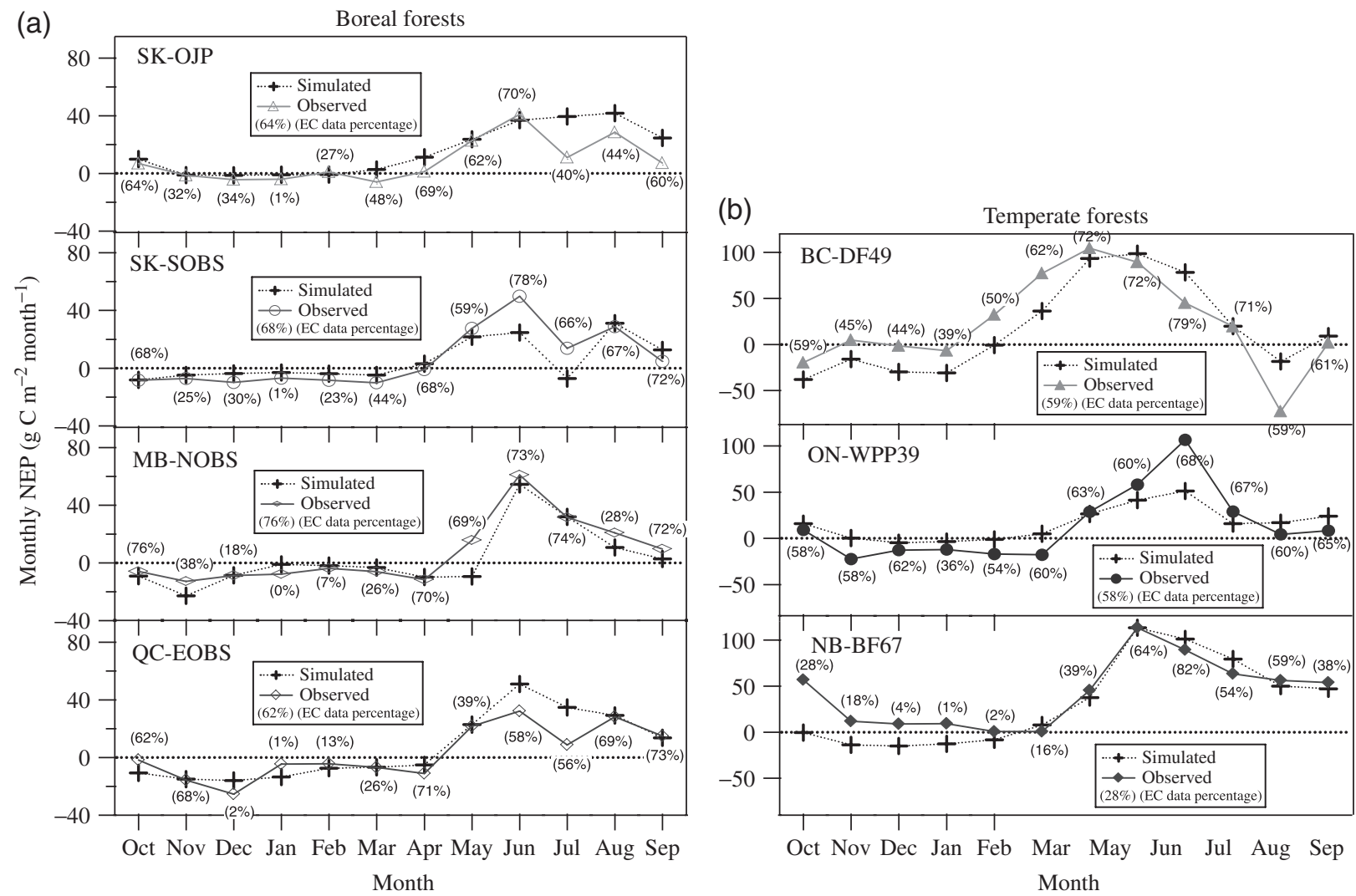

Fig. 4 Comparison of CN-CLASS simulated and measured (gap-filled) monthly NEP at all the seven conifer forest sites across Canada. Note that the percentage of nongap-filled measured data is shown for each month.

Table 5 Comparison of gap-filled EC observations and CN-CLASS simulations of annual C exchanges (NEP, GEP and RE; $\mathrm{gC} \mathrm{m}^{-2} \mathrm{yr}^{-1}$ ) from October 1, 2003 to September 30, 2004 at seven coniferous forest sites across Canada

\begin{tabular}{|c|c|c|c|c|c|c|}
\hline & \multicolumn{2}{|l|}{ GEP } & \multicolumn{2}{|l|}{$\mathrm{RE}$} & \multicolumn{2}{|l|}{$\mathrm{NEP}$} \\
\hline & Modeled & Observed & Modeled & Observed & Modeled & Observed \\
\hline \multicolumn{7}{|l|}{ Boreal forests } \\
\hline SK-OJP & 659 & 624 & 438 & 555 & 187 & 104 \\
\hline SK-SOBS & 780 & 745 & 742 & 674 & 58 & 72 \\
\hline MB-NOBS & 730 & 617 & 698 & 535 & 32 & 81 \\
\hline QC-EOBS & 701 & 702 & 624 & 666 & 77 & 37 \\
\hline $\mathrm{CV}$ & 8.2 & 9.3 & 21.5 & 11.9 & 76.9 & 38.6 \\
\hline \multicolumn{7}{|c|}{ Temperate forests } \\
\hline BC-DF49 & 2329 & 2368 & 2125 & 2095 & 204 & 273 \\
\hline ON-WPP39 & 1425 & 1477 & 1260 & 1315 & 164 & 162 \\
\hline NB-BF67 & 1411 & 1380 & 1005 & 871 & 406 & 508 \\
\hline $\mathrm{CV}$ & 30.5 & 31.3 & 40.1 & 43.4 & 50.3 & 56.2 \\
\hline
\end{tabular}

different than the response curves of the sensitivity tests at individual sites.

Annual GEP and RE showed no consistent response to variations in precipitation either among forests or within individual sites in this study (Fig. 5g-i). Although soil water status is a consequence of soil depth, texture and topography, forest ecosystems generally have higher infiltration rates that help them to retain relatively larger amount of rainwater in the root zone. This would be particularly true for established forests, which generally have a well-developed litter or even a humus layer and deep root zone. Sayer (2005) 

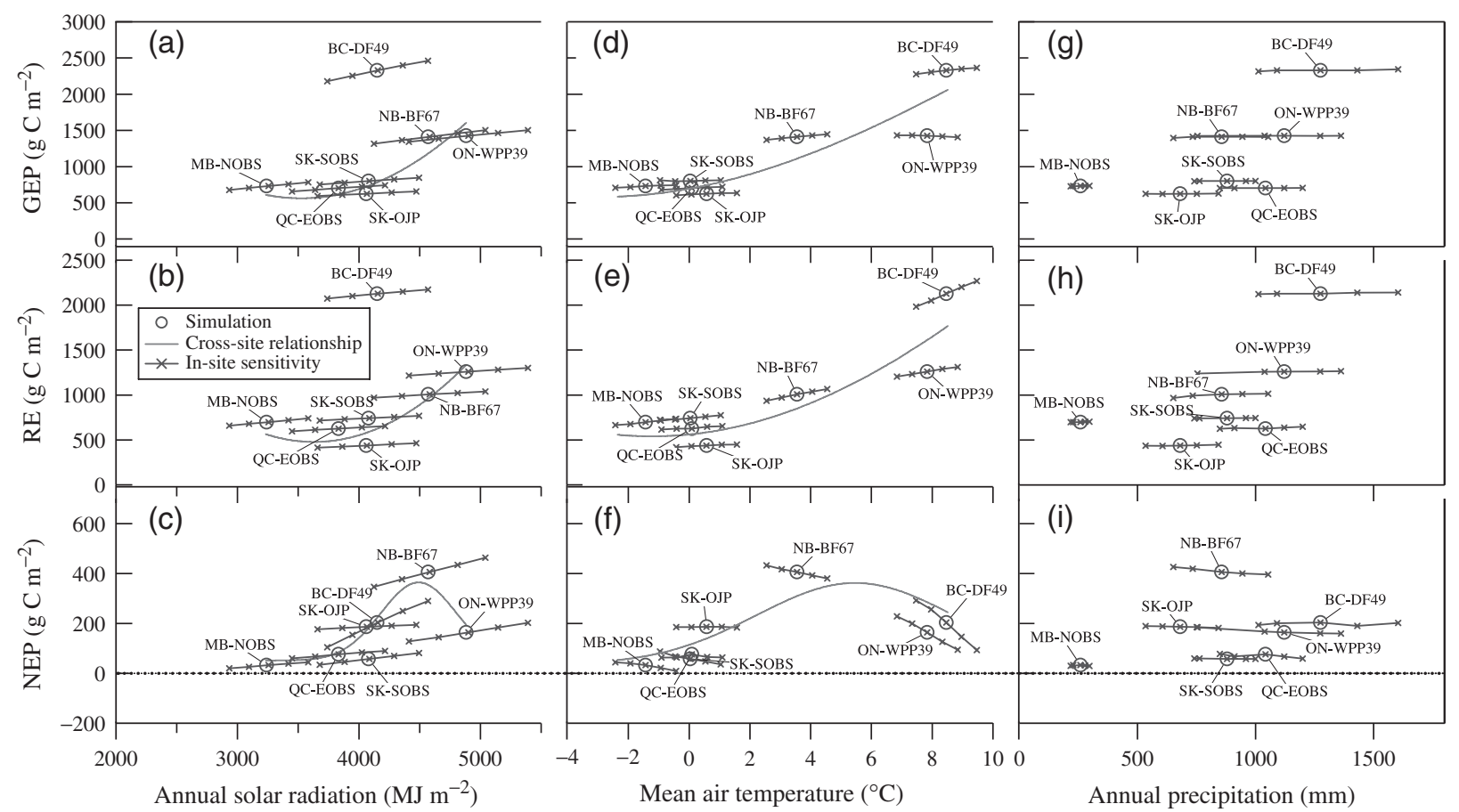

Fig. 5 Cross-site comparison of simulated annual GEP, RE and NEP, and in-site sensitivity to total solar radiation (a-c), mean air temperature $(\mathrm{d}-\mathrm{f})$ and total precipitation $(\mathrm{g}-\mathrm{i})$, at all the seven conifer forest sites across Canada. The sensitivity analysis at each forest site was conducted by changing incident solar radiation at $\pm 5 \%$ and $\pm 10 \%$, air temperature at \pm 0.5 and $\pm 1.0{ }^{\circ} \mathrm{C}$ and precipitation at $\pm 10 \%$ and $\pm 20 \%$ of observed values, respectively, and one at a time while the rest unchanged.

reported that the high water-retention capacity of litter and soil organic matter helps to maintain maximum infiltration rate and water penetration to deeper soil layers. In CN-CLASS, maximum root depth was set to $1 \mathrm{~m}$, which allowed higher portion of soil water to be utilized by trees and could partially explain results of this sensitivity analysis.

\section{Sensitivity of $C$ exchanges to aboveground biomass}

Unlike climatic conditions, which act as external forcing for ecosystem $C$ exchanges, the forest itself represents ecosystem's ability or capacity to uptake atmospheric $\mathrm{CO}_{2}$ and respire stored $\mathrm{C}$. This ability is related to forest characteristics, for example, nonliving substrate and aboveground living biomass. When all seven forests were pooled together, the annual GEP increased with aboveground biomass (Fig. 6a). A similar trend was observed in the RE vs. aboveground biomass relationship (Fig. 6b), but at high biomass, the rate of increase of RE (per unit biomass) exceeded that of GEP. This was because LAI, which generally increased with increasing biomass, reached a maximum value (logistic shape of the curve) for very high biomass values. At this stage, trees allocated more assimilates to other plant components as compared with leaves. Therefore, the rate of increase of RE was more than GEP, because both living and nonliving biomass contributed to RE, while only leaves could uptake $\mathrm{CO}_{2}$ through photosynthesis. Consequently NEP initially increased with aboveground biomass, but then started to decline with further increases in biomass (Fig. 6c).

Modeled GEP and RE were sensitive to $\pm 20 \%$ and $\pm 50 \%$ change in the aboveground biomass showing positive trends at each site, which were similar to cross-site patterns (Fig. 6a-b). Such a positive relationship was more obvious at the three intermediate-aged temperate forests (BC-DF49, ON-WPP39 and NB-BF67) than at the 4-year-old growth boreal forests, as shown by the steeper slopes of GEP and RE vs. aboveground biomass curves in Fig. 6a-c.

\section{Sensitivity $C$ exchanges to nonliving $C$ stocks}

In a forest, the nonliving soil $\mathrm{C}$ stock is comprised of two major components: litter and SOM, both of which are highly variable and site specific (Table 1). As expected, model sensitivity tests showed that increasing litter C stock had no impact on annual GEP (Fig. 6d), but it had a large positive impact on RE (Fig. 6e), resulting in a net negative impact on NEP (Fig. 6f). This was especially true at the BC-DF49 site that had large 


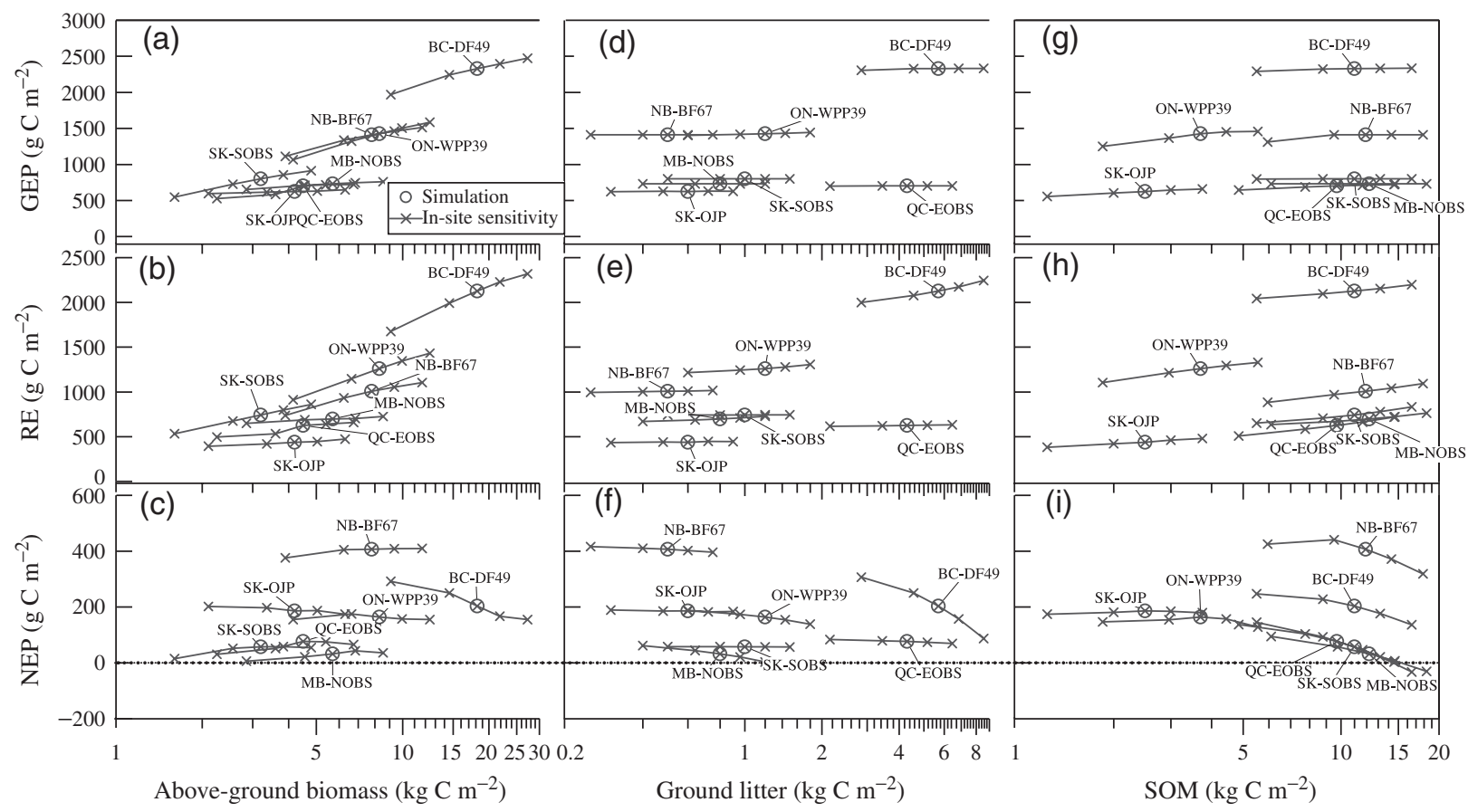

Fig. 6 Cross-site comparison of annual GEP, RE and NEP by primary $\mathrm{C}$ stocks: aboveground biomass (a-c), forest floor litter (d-f), and soil organic matter ( $\mathrm{g}-\mathrm{i})$ and in-site sensitivity analysis at all the seven conifer forest sites across Canada. Note that the $x$-axis is logarithm-scaled. The sensitivity was conducted by varying aboveground biomass by $\pm 20 \%$ and $\pm 50 \%$, litter by $\pm 20 \%$ and $\pm 50 \%$ and SOM by $\pm 20 \%$ and $\pm 50 \%$ of observed values, respectively, and one at a time while the rest unchanged.

litter accumulation under high annual air temperatures. At the four boreal forests, litter $\mathrm{C}$ might have some positive relationship to RE, but not at all boreal forests (Fig. 6e). As for SOM, annual GEP, RE and NEP were unrelated to the $\mathrm{C}$ content across sites (Fig. 6g-i). At each site, however, the model sensitivity analysis showed that GEP was affected by reduced SOM at two sites, SK-OJP and ON-WPP39. Both sites had low soil C content, especially in the humus pool (Table 1). A similar effect on GEP was observed at BC-DF49 and NB-BF67, but, only when SOM was reduced to $50 \%$ of the observed values. This was a result of enhanced soil nutrient $(\mathrm{N})$ supply, accompanied with relatively higher mineralization rates, when SOM was increased at a site where SOM content was initially in a low range. Such an effect is diminished when SOM accumulation is very high. On the other hand, changes in annual RE were sensitive to SOM, but the sensitivity was greatest at low SOM and decreased with increasing SOM. These effects of SOM (indirectly on GEP and directly on RE) impacted annual NEP differently in each forest, as shown in Fig. 6i. In forests with higher SOM, only RE was affected by SOM (direct effect); while in forests with very low SOM, both GEP (indirect effect through nutrient supply) and RE were affected by SOM.

\section{Discussion}

\section{Simulated and observed $\mathrm{C}$ exchanges}

This site inter-comparison study analyzed the observed and simulated $\mathrm{CO}_{2}$ fluxes at four mature boreal and three intermediate-aged temperate forests across an east-west continental gradient in Canada. As much as possible, simulations were performed using less sitespecific parameters for targeted study forests. Unlike the prescribed site-specific $V_{\text {cmax }}$ values used previously in Arain et al. (2002), Grant et al. (2006) etc, the use of leaf Rubisco-N and canopy temperature to calculate the seasonal dynamic of $V_{\text {cmax }}$ (and thus $J_{\text {cmax }}$ ) improved the simulation of photosynthesis at all the seven study sites. The leaf Rubisco-N status was closely associated with soil-plant $\mathrm{N}$ cycling and canopy temperature was related to site energy balance. The coupling of $\mathrm{C}$ and $\mathrm{N}$ cycling in the model allowed the investigation of the role of nutrients in modulating forest $C$ exchanges under various environmental conditions. Physiologically and biochemically, photosynthesis is constrained, not by total leaf $\mathrm{N}$, but by leaf Rubisco-N and its activity status (Jiang et al., 1993; Dickinson et al., 2002; Warren \& Adams, 2004; Ainsworth \& Long, 2005). In an established forest, leaf N 
status (and thus Rubisco-N) represents both plant growth demand and soil-plant $\mathrm{N}$ cycling under local conditions. In this study, CN-CLASS was initialized using site-specific observed soil organic $\mathrm{C}$ and $\mathrm{N}$ data and was spun-up for 10 years. This spin-up procedure ensured that simulated leaf $\mathrm{N}$ and Rubisco-N contents were in steady-state and depended on site $\mathrm{C}$ and $\mathrm{N}$ processes, which were influenced by soil organic $\mathrm{C}$ and $\mathrm{N}$ contents and environmental factors (e.g. moisture and temperature). Modeled leaf Rubisco-N concentration varied much more across sites (and regions) than seasonally at individual site. The model was able to produce $V_{\text {cmax }}$ dynamics so that simulated GEP reasonably well at each site. The small underestimation of winter GEP at the three temperate forests (especially BC-DF49), indicated that further improvement in the temperature response functions for $V_{\mathrm{cmax}}$ and $J_{\max }$ [Eqns (A1) and (A2)] are required to capture $C$ uptake during relatively mild winters and early springs.

The simulation of the daily and seasonal cycles of RE was not as accurate as that of GEP for all sites, but it was within acceptable uncertainty limits. The $R^{2}$ for simulated and observed RE ranged from 0.65 to 0.87 , while the corresponding values for GEP were 0.81-0.88. Unlike photosynthetic processes, which are based on a well-established theoretical understanding, RE involves a number of complex processes that cause difficulties in its modeling and subsequent comparison with measurements at ecosystem level (Trumbore, 2006). These processes are represented simply, as first-order equations and are controlled by a number of factors, including temperature, moisture, biomass and heterogeneity in substrate $C$ stocks. In this study, a single set of reference respiration rates was used for each of the four living biomass and three dead C pools for all the seven conifer forests (Table 3). Temperature and/or moisture response functions were also the same for all the seven sites. RE was generally underestimated in winter at all sites. During the growing season, RE errors were partly associated with the bias between simulated and observed GEP at two of the sites (MB-NOBS and ONWPP39). For the other sites, differences in simulated and observed RE values were caused by uncertainty in various sub-components of RE due to either the simulations or the estimation from eddy covariance observations. Another source of uncertainty is the ecosystem C stocks at the study sites. These stocks are heterogeneous and difficult to measure in the footprint of the flux tower, as highlighted by the broad range of values reported by different researchers at the SK-SOBS and SK-OJP sites. Despite these uncertainties, the CN-CLASS model generally performed very well in terms of seasonal patterns and annual values of GEP, RE and NEP at all the seven forest sites.

\section{Carbon exchange characteristics among sites}

The four mature boreal forest sites analyzed in this study were weak $\mathrm{C}$ sinks ranging from 30 to more than $100 \mathrm{~g} \mathrm{C} \mathrm{m}^{-2} \mathrm{yr}^{-1}$. The intermediate-aged temperate forests were moderate-to-strong $C$ sinks ranging from 160 to $500 \mathrm{~g} \mathrm{C} \mathrm{m}^{-2}$. These Canadian boreal forests fell within the median range of $C$ sequestration reported in literature for boreal forest ecosystems [i.e. -200$250 \mathrm{~g} \mathrm{C} \mathrm{m}^{-2} \mathrm{yr}^{-1}$ (Hyvonen et al., 2007)]. The temperate forests were within the lower range of NEP values reported for the temperate ecosystems across the world, [i.e. $250-700 \mathrm{~g} \mathrm{C} \mathrm{m}^{-2} \mathrm{yr}^{-1}$ (Hyvonen et al., 2007)], probably because of their relatively higher latitude locations.

In this study, the seasonal NEP changes showed a period of relatively low net $\mathrm{C}$ uptake during the main growing season, except for the MB-NOBS site, resulting in 'bimodal' patterns in the time course of NEP (Fig. 4). The summertime depression in NEP, following late spring NEP peaks, corresponded to peak RE due to relatively high temperature and/or seasonal soil dryness resulting from reduced rainfall at some of the sites. The secondary NEP peak in the growing season, mostly lower than the late spring one, reflected the higher sensitivity of RE than GEP to the decline in temperature. MB-NOBS site was an exception, because the RE peak occurred later in the growing season at this site than at the other boreal forests. The CN-CLASS was able to capture these seasonal trends although it could not exactly match up the bimodal pattern at all the sites, possibly because of small differences in model's ability to simulate soil and plant temperature and/or moisture status.

The inter-site differences of annual GEP, RE and NEP were smaller among the four boreal forest sites compared with the three temperate forests (see CV in Table $5)$. The large differences among the three temperate forests resulted from the extraordinarily high GEP and $\mathrm{RE}$ at the BC-DF49, probably due to the high site productivity (tall and large $d_{\mathrm{bh}}$ with considerable biomass, high LAI and litter/SOM accumulations), mild winters and longer growing seasons. Less litter accumulation was observed at the NB-BF67, the youngest of the three temperate forests. In addition, air temperature was much lower at NB-BF67 than at the other two sites. Therefore, a much lower RE (thus higher NEP) was observed and modeled at this forest site.

\section{Climatic and biophysical controls on $C$ exchanges}

It is a challenge to distinguish environmental or climatic controls from factors reflecting biological/physiologi$\mathrm{cal} /$ biophysical status of an ecosystem that contributes to differences in annual $\mathrm{C}$ exchanges. This analysis 
indicated that air temperature among climate factors and aboveground 'living' biomass among major $\mathrm{C}$ stocks played dominant roles in GEP, RE and NEP at these established or old forests. Temperature impacts on GEP, RE and NEP were highly nonlinear and varied from site to site. Overall, increased air temperature slightly increased GEP on an annual basis at each site. Within the prescribed range $\left( \pm 0.5- \pm 1.0^{\circ} \mathrm{C}\right)$, explored in this modeling study, air temperature impacted photosynthetic activity through plant stomatal closure, by increasing VPD (results not shown). The model applied a commonly used algorithm, the BallWoodrow-Berry equation [Eqn (A4)], to simulate photosynthesis-canopy conductance relationship, which included the effects of VPD and root zone soil moisture. In our temperature sensitivity tests, temperature changed, but specific humidity and precipitation remained unchanged. Therefore, temperature variations affected the saturation vapor pressure, and hence VPD. Higher temperature meant higher ET, and thus drier soils. Temperature increase also rapidly enhanced $\mathrm{RE}$, because of direct effects on soil temperature and possibly indirect impacts on soil water content. Therefore, air temperature had a dominant effect on the annual cycle of NEP compared with all other factors, because of its dual impact on both GEP and RE.

Downwelling solar radiation was a limiting factor for photosynthesis. However, small variations (5-10\%) played a relatively small role in the overall $C$ budgets in these well-established older forests. Sensitivity analysis showed that photosynthesis increased approximately linearly with incident solar radiation, which appeared to be similar for all the sites.

Variations in precipitation alone had little effect on $\mathrm{C}$ cycling in these forests. The impact of precipitation was indirect, via changes in soil water status. However, the changes in soil water were buffered by the waterholding capacity of the LFH and A horizon of these forest soils. Recently, Kljun et al. (2006) argued that although the $\mathrm{C}$ budgets of boreal forests strongly depend on regional patterns of precipitation, soil characteristics and topography, boreal coniferous stands growing in low-lying peat soils (e.g. SK-SOBS) or coarse textured sandy soils (e.g. SK-SOJP) may not be severely affected by short-term variations in precipitation. However, a recent long-term study at MB-NOBS (Dunn et al., 2007) indicated that the boreal forests showed decadal trends in climatic controls and that some factors act over multi-year time scales. In particular, variation in water table depth in response to changes in precipitation may strongly influence the $\mathrm{C}$ budgets on annual time scales. Therefore, longer term data and modeling studies are required to fully ascertain the impact of climate controls on boreal forest ecosystems, particularly precipitation and soil water status, which may operate at much longer time scales than a year.

Over longer and historic time scales, geographic variations in climate and soils lead to geographic variations in vegetation composition and productivity, which, in turn, affect biomass accumulation and ecosystem $\mathrm{C}$ exchange. However, under similar climate and soil conditions, ecosystem biomass itself may be one of the factors affecting net ecosystem $\mathrm{C}$ exchange: directly through autotrophic respiration and indirectly through photosynthetic allocation to leaves (LAI) and thus its influence on GEP. In Fig. 5, the sensitivity of GEP, RE and NEP to variations in solar radiation, temperature and precipitation at individual sites differed from the cross-site trends, implying that these three climatic factors alone could not explain site differences in $C$ exchanges in this study. In Fig. 6a-c, GEP, RE and NEP responded to aboveground biomass somehow similar both within and among forest sites. This implied that aboveground biomass also affected ecosystem $\mathrm{C}$ exchanges along with climatic variables. Therefore, variations in aboveground biomass, that may occur due to fire, harvesting, re-growth, stand age, etc., could help to explain variations in ecosystem $\mathrm{C}$ exchange across sites under similar soil and climatic conditions.

Compared with well-humidified SOM, forest floor litter had a higher $\mathrm{C} / \mathrm{N}$ ratio, because it was partially decomposed. Therefore, litter made less $\mathrm{N}$ available to plants compared with SOM. Consequently, photosynthesis (and leaf $\mathrm{N}$ ) was less influenced by the litter accumulation. In contrast, soils with little SOM may have low rates of $\mathrm{N}$ mineralization and a sensitive response of photosynthesis to low SOM content, as demonstrated by the GEP sensitivity to SOM C reduction at two relatively low SOM sites (SK-OJP and ONWPP39).

In summary, model sensitivity tests of key climatic controls and primary $\mathrm{C}$ stocks demonstrated that C exchanges in geographically distributed forest ecosystems are affected differently by these controls. Sitespecific observations and corresponding modeling studies may incorrectly or incompletely draw conclusions on the effects of targeted factors. Comparing the sensitivity of these controls at individual sites with patterns across multiple sites, using a modeling approach, should provide a useful tool to analyze or distinguish the controls on ecosystem $\mathrm{C}$ exchange in larger geographic regions.

\section{Conclusions}

The CN-CLASS model was able to successfully simulate half-hourly, daily and seasonal $C$ exchanges, estimated using the eddy covariance technique at four boreal and 
three temperate coniferous forests along an east-west continental transect in Canada. A single set of parameters was used for all the seven sites, except two parameters, one of which controlled the empirical canopy conductance relationship and the other determined leaf area relationship to sapwood (pipe theory). Leaf Rubisco-N dynamics and activity were closely associated with soil-plant $\mathrm{N}$ cycling and energy balance. Leaf Rubisco-N varied from site to site, and predicted site-specific photosynthesis reasonably well.

Both observed and simulated data showed that mature boreal forests were either carbon-neutral or a weak carbon sinks, ranging from 30 to $180 \mathrm{~g} \mathrm{C} \mathrm{m}^{-2} \mathrm{yr}^{-1}$. The intermediate-aged temperate forests were either a medium or strong sink of carbon, ranging from 150 to $500 \mathrm{~g} \mathrm{C} \mathrm{m}^{-2} \mathrm{yr}^{-1}$, depending on stand age and climatic conditions. Differences in the seasonal dynamics of GEP and RE, because of their varying responses to climatic conditions, resulted in a NEP peak in June in boreal forests and April/May-May/June in temperate forests. The NEP peak was followed by a mid-summer period of near-zero NEP corresponding to peak RE, while a secondary NEP peak occurred in late summer. Generally, GEP simulations were better than RE on a seasonal and annual basis. The improvements in the model's photosynthesis module were made to accommodate winter C uptake observed during mild conditions in temperate regions. However, further work is needed to accurately capture winter $\mathrm{C}$ uptake at both coastal temperate sites. On the other hand, further measurements of site-specific characteristics, $C$ stocks and other parameters are also required to appropriately model RE at the ecosystem level.

Model sensitivity tests indicated that air temperature, among climate factors and aboveground biomass among major $\mathrm{C}$ pools, played primary roles in seasonal and annual $\mathrm{C}$ exchange in the studied forests, followed by soil organic matter and litter $C$ contents, which had a small impact on $\mathrm{C}$ cycling depending upon site conditions and the amount of $\mathrm{C}$ stored. Incident solar radiation was also a limiting factor for GEP, RE and NEP. Small variations in precipitation may not have a large impact on $\mathrm{C}$ cycling in these well-established forest ecosystems. However, the modeling analysis demonstrated that these effects on ecosystem $C$ balance varied nonlinearly from site to site.

\section{Acknowledgements}

This research was supported by the Canadian Foundation for Climate and Atmospheric Sciences (CFCAS) through Canadian Global Coupled Carbon Climate Modelling project (PIs: Nigel Roulet and Ken Denman) and CFCAS, the Natural Sciences and Engineering Research Council (NSERC) and the BIOCAP
Canada Foundation through the Fluxnet-Canada Research Networks (PI: Hank Margolis), and as well the CFCAS-BIOCAP funded Canadian Carbon Program (CCP). The Fluxnet-Canada field measurements also received support from the Climate Research Division of Environment Canada and the Canadian Forest Service. We acknowledge the provision of data from the Turkey Point Flux Station and the Northern Old Black Spruce (NOBS) sites. The Turkey Point Flux Station is an associated site of FCRN/CCP (funded by NSERC, CFI and OIT). We thank Diana Verseghy for her advice in model development. We acknowledge graduate students, postdoctoral fellows, research associates and technicians in all groups at each relevant institution across the FCRN and CCP networks for their contributions to data collection and analysis and Myroslava Khomik for her editorial help. We appreciate the help of the FCRN/CCP Data Information System (DIS) for their efforts in data compilation.

\section{References}

Ainsworth EA, Long SP (2005) What have we learned from 15 years of free-air $\mathrm{CO}_{2}$ enrichment (FACE)? A meta-analytic review of the responses of photosynthesis, canopy properties and plant production to rising $\mathrm{CO}_{2}$. New Phyotologist, 165, 351-372.

Anderson DW (2000) BOREAS TE-01 SSA Soil Lab Data. http:/ / www.daac.ornl.gov (Last accessed 2/25/2007). Oak Ridge National Laboratory Distributed Active Archive Center, Oak Ridge, TN, USA.

Arain MA, Black TA, Barr AG, Jarvis PG, Massheder JM, Verseghy DL, Nesic Z (2002) Effects of seasonal and interannual climate variability on net ecosystem productivity of boreal deciduous and conifer forests. Canadian Journal of Forest Research - Revue Canadienne De Recherche Forestiere, 32, 878-891.

Arain MA, Restrepo-Coupe N (2005) Net ecosystem production in a temperate pine plantation in southeastern Canada. Agricultural and Forest Meteorology, 128, 223-241.

Arain MA, Yuan F, Andrew Black T (2006) Soil-plant nitrogen cycling modulated carbon exchanges in a western temperate conifer forest in Canada. Agricultural and Forest Meteorology, 140, 171-192.

Arora VK, Boer GJ (2005) A parameterization of leaf phenology for the terrestrial ecosystem component of climate models. Global Change Biology, 11, 39-59.

Aubinet M, Grelle A, Ibrom A et al. (2000) Estimates of the annual net carbon and water exchange of forests: the EUROFLUX methodology, advances in ecological research. Advances in Ecological Research, 30, 113-175.

Baldocchi D, Falge E, Gu LH et al. (2001) FLUXNET: a new tool to study the temporal and spatial variability of ecosystem-scale carbon dioxide, water vapor, and energy flux densities. Bulletin of the American Meteorological Society, 82, 2415-2434.

Baldocchi DD, Vogel CA (1996) Energy and $\mathrm{CO}_{2}$ flux densities above and below a temperate broad-leaved forest and a boreal pine forest. Tree Physiology, 16, 5-16.

Baldocchi DD, Vogel CA, Hall B (1997) Seasonal variation of carbon dioxide exchange rates above and below a boreal jack pine forest. Agricultural and Forest Meteorology, 83, 147-170.

Ball JT, Woodrow IE, Berry JA (1987) A model predicting stomatal conductance and its contribution to the control of 
phtotosynthesis under different environmental conditions. In: Progress in Photosynthesis Research (ed. Biggens J), pp. 221-224. Martinus-Nijhoff, Dordrecht, the Netherlands.

Barr AG, Black TA, Hogg EH, Kljun N, Morgenstern K, Nesic Z (2004) Inter-annual variability in the leaf area index of a boreal aspen-hazelnut forest in relation to net ecosystem production. Agricultural and Forest Meteorology, 126, 237-255.

Bergeron O, Margolis HA, Black TA, Coursolle C, Dunn AL, Barr AG, Wofsy SC (2007) Comparison of carbon dioxide fluxes over three boreal black spruce forests in Canada. Global Change Biology, 13, 89-107.

Cen YP, Sage RF (2005) The regulation of rubisco activity in response to variation in temperature and atmospheric $\mathrm{CO}_{2}$ partial pressure in sweet potato. Plant Physiology, 139, 979-990.

Chen JM, Govind A, Sonnentag O, Zhang Y, Barr A, Amiro B (2006) Leaf area index measurements at Fluxnet-Canada forest sites. Agricultural and Forest Meteorology, 140, 257-268.

Coursolle C, Margolis HA, Barr AG et al. (2006) Late-summer carbon fluxes from Canadian forests and peatlands along an east-west continental transect. Canadian Journal of Forest Research - Revue Canadienne De Recherche Forestiere, 36, 783-800.

Dickinson RE, Berry JA, Bonan GB et al. (2002) Nitrogen controls on climate model evapotranspiration. Journal of Climate, 15, 278-295.

Dolman AJ, Noilhan J, Durand P et al. (2006) The CarboEurope regional experiment strategy. Bulletin of the American Meteorological Society, 87, 1367.

Dunn AL, Barford CC, Wofsy SC, Goulden ML, Daube BC (2007) A long-term record of carbon exchange in a boreal black spruce forest: means, responses to interannual variability, and decadal trends. Global Change Biology, 13, 577-590.

Falge E, Baldocchi DD, Olson RJ et al. (2001) Gap filling strategies for defensible annual sums of net ecosystem exchange. Agricultural and Forest Meteorology, 107, 43-69.

Falge E, Reth S, Bruggemann N et al. (2005) Comparison of surface energy exchange models with eddy flux data in forest and grassland ecosystems of Germany. Ecological Modelling, 188, 174-216.

Friend AD, Arneth A, Kiang NY et al. (2007) FLUXNET and modelling the global carbon cycle. Global Change Biology, 13, 611-630.

Gower ST, Vogel JG, Norman JM, Kucharik CJ, Steele SJ, Stow TK (1997) Carbon distribution and aboveground net primary production in aspen, jack pine, and black spruce stands in Saskatchewan and Manitoba, Canada. Journal of Geophysical Research - Atmospheres, 102, 29029-29041.

Grant RF, Arain A, Arora V et al. (2005) Intercomparison of techniques to model high temperature effects on $\mathrm{CO}_{2}$ and energy exchange in temperate and boreal coniferous forests. Ecological Modelling, 188, 217-252.

Grant RF, Goulden ML, Wofsy SC, Berry JA (2001) Carbon and energy exchange by a black spruce-moss ecosystem under changing climate: testing the mathematical model ecosys with data from the BOREAS experiment. Journal of Geophysical Research - Atmospheres, 106, 33605-33621.

Grant RF, Zhang Y, Yuan F et al. (2006) Intercomparison of techniques to model water stress effects on $\mathrm{CO}_{2}$ and energy exchange in temperate and boreal deciduous forests. Ecological Modelling, 196, 289-312.

Griffis TJ, Black TA, Morgenstern K et al. (2003) Ecophysiological controls on the carbon balances of three southern boreal forests. Agricultural and Forest Meteorology, 117, 53-71.

Gu LH, Baldocchi D (2002) Fluxnet 2000 synthesis - foreword. Agricultural and Forest Meteorology, 113, 1-2.

Harden JW, O'Neill KP, Trumbore SE, Veldhuis H, Stocks BJ (1997) Moss and soil contributions to the annual net carbon flux of a maturing boreal forest. Journal of Geophysical Research Atmospheres, 102, 28805-28816.

Humphreys ER, Black TA, Morgenstern K, Cai T, Drewitt GB, Nesic Z, Trofymow JA (2006) Carbon dioxide fluxes in three coastal Douglas-fir stands at different stages of development after harvesting. Agricultural and Forest Meteorology, 140, 6-22.

Hyvonen R, Agren GI, Linder S et al. (2007) The likely impact of elevated $\left[\mathrm{CO}_{2}\right]$, nitrogen deposition, increased temperature and management on carbon sequestration in temperate and boreal forest ecosystems: a literature review. New Phytologist, 173, 463-480.

Ishag KHM, Dennett MD (1998) Use of the expolinear growth model to analyse the growth of faba bean, peas and lentils at three densities: fitting the model. Annals of Botany, 82, 497-505.

Jarvis PG, Massheder JM, Hale SE, Moncrieff JB, Rayment M, Scott SL (1997) Seasonal variation of carbon dioxide, water vapor, and energy exchanges of a boreal black spruce forest. Journal of Geophysical Research - Atmospheres, 102, 28953-28966.

Jiang CZ, Rodermel SR, Shibles RM (1993) Photosynthesis, Rubisco activity and amount, and their regulation by transcription in senescing soybean leaves. Plant Physiology, 101, 105-112.

Keser N, St Pierre D (1973) Soils of Vancouver Island: A compendium. BC Forest Sevice Research Note 56 - Hart soil.

Kljun N, Black TA, Griffis TJ et al. (2006) Response of net ecosystem productivity of three boreal forest stands to drought. Ecosystems, 9, 1128-1144.

Kramer K, Leinonen I, Bartelink HH et al. (2002) Evaluation of six process-based forest growth models using eddy-covariance measurements of $\mathrm{CO}_{2}$ and $\mathrm{H}_{2} \mathrm{O}$ fluxes at six forest sites in Europe. Global Change Biology, 8, 213-230.

Kucharik CJ, Barford CC, Maayar ME, Wofsy SC, Monson RK, Baldocchi DD (2006) A multiyear evaluation of a dynamic global vegetation model at three AmeriFlux forest sites: vegetation structure, phenology, soil temperature, and $\mathrm{CO}_{2}$ and $\mathrm{H}_{2} \mathrm{O}$ vapor exchange. Ecological Modeling, 196, 1-31.

Leuning R (2002) Temperature dependence of two parameters in a photosynthesis model. Plant, Cell and Environment, 25, 1205-1210.

Litton CM, Ryan MG, Tinker DB, Knight DH (2003) Belowground and aboveground biomass in young postfire lodgepole pine forests of contrasting tree density. Canadian Journal of Forest Research - Revue Canadienne De Recherche Forestiere, 33, 351-363.

Margolis HA, Flanagan LB, Amiro BD (2006) The FluxnetCanada research network: influence of climate and disturbance on carbon cycling in forests and peatlands. Agricultural and Forest Meteorology, 140, 1-5. 
Medlyn BE, Berbigier P, Clement R et al. (2005a) Carbon balance of coniferous forests growing in contrasting climates: modelbased analysis. Agricultural and Forest Meteorology, 131, 97-124.

Medlyn BE, Dreyer E, Ellsworth D et al. (2002) Temperature response of parameters of a biochemically based model of photosynthesis. II. A review of experimental data. Plant Cell and Environment, 25, 1167-1179.

Medlyn BE, Robinson AP, Clement R, McMurtrie RE (2005b) On the validation of models of forest $\mathrm{CO}_{2}$ exchange using eddy covariance data: some perils and pitfalls. Tree Physiology, 25, 839-857.

Melesse AM, Hanley RS (2005) Artificial neural network application for multi-ecosystem carbon flux simulation. Ecological Modelling, 189, 305-314.

Morales P, Sykes MT, Prentice IC et al. (2005) Comparing and evaluating process-based ecosystem model predictions of carbon and water fluxes in major European forest biomes. Global Change Biology, 11, 2211-2233.

Morgenstern K, Black TA, Humphreys ER et al. (2004) Sensitivity and uncertainty of the carbon balance of a Pacific Northwest Douglas-fir forest during an El Niño La Nina cycle. Agricultural and Forest Meteorology, 123, 201-219.

Papale D, Valentini R (2003) A new assessment of European forests carbon exchanges by eddy fluxes and artificial neural network spatialization. Global Change Biology, 9, 525-535.

Peichl M, Arain MA (2006) Above- and belowground ecosystem biomass and carbon pools in an age-sequence of temperate pine plantation forests. Agricultural and Forest Meteorology, 140, 51-63.

Piao S, Ciais P, Friedlingstein P et al. (2008) Net carbon dioxide losses of northern ecosystems in response to autumn warming. Nature, 451, 49-53.

Presant EW, Acton CJ (1984) The soils of the regional municipality of Haldimand - 928 Norfolk. Report No. 57, Agriculture Canada, Ministry of Agriculture and Food, Guelph, Ontario.

Raupach MR, Rayner PJ, Barrett DJ et al. (2005) Model-data synthesis in terrestrial carbon observation: methods, data requirements and data uncertainty specifications. Global Change Biology, 11, 378-397.

Sayer EJ (2005) Using experimental manipulation to assess the roles of leaf litter in the functioning of forest ecosystems. Biological Reviews, 81, 1-31.

Schwalm CR, Black TA, Amiro BD et al. (2006) Photosynthetic light use efficiency of three biomes across an east-west continental-scale transect in Canada. Agricultural and Forest Meteorology, 140, 269-286.

Sellers PJ, Hall FG, Kelly RD et al. (1997) BOREAS in 1997: experiment overview, scientific results, and future directions. Journal of Geophysical Research - Atmospheres, 102, 28731-28769.

Trumbore S (2006) Carbon respired by terrestrial ecosystems recent progress and challenges. Global Change Biology, 12, 141-153.

Turner DP, Acker SA, Means JE, Garman SL (2000) Assessing alternative allometric algorithms for estimating leaf area of Douglas-fir trees and stands. Forest Ecology and Management, 126, 61-76.

Veldhuis H (2000) BOREAS TE-20 NSA Soil Lab Data. http:/ / www.daac.ornl.gov (Last accessed 2/25/2007). Oak Ridge
National Laboratory Distributed Active Archive Center, Oak Ridge, TN, USA.

Verseghy DL (1991) CLASS - a Canadian land surface scheme for GCMS. 1. Soil model. International Journal of Climatology, 11, 111-133.

Verseghy DL, McFarlane NA, Lazare M (1993) CLASS - a Canadian land-surface scheme for GCMS. 2. Vegetation model and coupled runs. International Journal of Climatology, 13, 347-370.

Wang S, Grant RF, Verseghy DL, Black TA (2001) Modelling plant carbon and nitrogen dynamics of a boreal aspen forest in CLASS - the Canadian land surface scheme. Ecological Modelling, 142, 135-154.

Warren CR, Adams MA (2004) Evergreen trees do not maximize instantaneous photosynthesis. Trends in Plant Science, 9, 270-274.

Xing ZS, Bourque CPA, Swift DE, Clowater CW, Krasowski M, Meng FR (2005) Carbon and biomass partitioning in balsam fir (Abies balsamea). Tree Physiology, 25, 1207-1217.

Yan WK, Hunt LA (1999) An equation for modelling the temperature response of plants using only the cardinal temperatures. Annals of Botany, 84, 607-614.

Yu GR, Wen XF, Sun XM, Tanner BD, Lee XH, Chen JY (2006) Overview of ChinaFLUX and evaluation of its eddy covariance measurement. Agricultural and Forest Meteorology, 137, $125-137$.

Yuan F, Arain MA, Black TA, Morgenstern K (2007) Energy and water exchanges modulated by soil-plant nitrogen cycling in a temperate Pacific Northwest conifer forest. Ecological Modelling, 201, 331-347.

\section{Appendix}

\section{Key model equations in this study}

In CN-CLASS, two key parameters, $V_{\text {cmax }}$ (the maximum carboxylation rate of Rubisco in leaves) and $J_{\max }$ (the potential rate of whole-chain electron transport) are used to calculate net $\mathrm{CO}_{2}$ fixation, $A_{\text {net }}$ as the minimum of Rubisco-limited and RuBP-limited gross photosynthesis. $V_{\text {cmax }}$ and $J_{\max }$ are nonlinearly related to leaf Rubisco-N content, which is dynamically associated with the soil-plant $\mathrm{N}$ cycle as shown below.

$$
\begin{gathered}
V_{\text {cmax }}=V_{\text {cmax }}\left(N_{\text {rub }}\right) \times f\left(T_{\text {leaf }}\right) \\
J_{\max }=2.1 V_{\text {cmax }}\left(N_{\text {rub }}\right)\left[0.15+0.85 f\left(T_{\text {leaf }}\right)\right],
\end{gathered}
$$

where $V_{\text {cmax }}\left(N_{\text {rub }}\right)$ is a function of Rubisco-N content at the top of the canopy.

$$
V_{\text {cmax }}\left(N_{\text {rub }}\right)=\alpha\left[1-\exp \left(-1.80 N_{\text {rub }}\right)\right],
$$

where, $\alpha$ is maximum value of $V_{\text {cmax }}$ and $N_{\text {rub }}$ is leaf Rubisco$\mathrm{N}\left(\mathrm{g} \mathrm{N} \mathrm{m}^{-2}\right.$ leaf area) at the top of the canopy, estimated from the total amount of $\mathrm{N}$ in the entire canopy (Arain et al., 2006).

In CN-CLASS, the $V_{\text {cmax }}$ (and $J_{\max }$ ) for sunlit and shaded big leaves is calculated using a single response function for temperature sensitivity:

$$
f\left(T_{\text {leaf }}\right)=\frac{T_{\text {max }}-T_{\text {leaf }}}{T_{\text {max }}-T_{\text {opt }}}\left(\frac{T_{\text {leaf }}-T_{\text {min }}}{T_{\text {opt }}-T_{\text {min }}}\right)^{\frac{T_{\text {opt }-T_{\min }}}{T_{\max -T_{\min }}},}
$$


where $T_{\text {leaf }}$ is the leaf temperature in ${ }^{\circ} \mathrm{C}$, and $T_{\min }, T_{\text {opt }}$ and $T_{\text {max }}$ are the minimum, optimum and maximum temperature for $V_{\text {cmax }}$ and $J_{\text {max }}$, respectively (Table 3). Experimental studies and multiple site meta-analysis have indicated that the $T_{\text {opt }}$ for $J_{\max }$ generally tended to be lower than $T_{\text {opt }}$ for $V_{\text {cmax }}$ (Leuning, 2002; Medlyn et al., 2002; Cen \& Sage, 2005). They also showed that the $T_{\min }$ for $J_{\max }$ might be below freezing. However, Eqn (A3) cannot capture this feature mathematically because it implicitly uses a minimum temperature of $0{ }^{\circ} \mathrm{C}$ (Yan \& Hunt, 1999). This limitation does not affect model parameterization at a single site, as has been demonstrated previously by Arain et al. (2006). However, for multiple sites located in diverse environments, the use of Eqn (A3) may introduce some level of uncertainty in the calculation of $V_{\mathrm{cmax}}$ and $J_{\max }$. Therefore, in this multiple-site study, different values of $T_{\min }$ and $T_{\text {opt }}$ were used for both $V_{\text {cmax }}$ and $J_{\max }$ calculations, but same values of $T_{\min }$ and $T_{\text {opt }}$ for $V_{\text {cmax }}$ and $J_{\max }$ were used for all the seven study sites (Table 3 ).

In CN-CLASS, canopy conductance for water vapor, $G_{\mathrm{c}}(1.56$ times of that for $\mathrm{CO}_{2}$ ) is sensitive to $A_{\text {net }}$ leaf surface $\mathrm{CO}_{2}$ concentration $\left(C_{\mathrm{s}}\right)$, vapor pressure deficit, VPD at the leaf surface $\left(D_{\mathrm{s}}\right)$ and soil root zone water availability $\left(f_{\theta \mathrm{s}}\right.$, from soil water module; Ball et al., 1987; Arain et al., 2002):

$$
G_{\mathrm{c}}=G_{\mathrm{c} 0}+\frac{a_{1} \times f\left(\theta_{\mathrm{s}}\right) \times A_{\text {net }}}{\left(C_{\mathrm{s}}-\Gamma\right)\left(1+D_{\mathrm{s}} / D_{0}\right)}
$$

where $G_{\mathrm{c} 0}$ is the residual stomatal conductance $\left(\mathrm{mol} \mathrm{m}^{-2} \mathrm{~s}^{-1}\right)$, $D_{0}$ is an empirical coefficient for sensitivity of stomata to $D_{\mathrm{s}}$ and $\Gamma$ is the $\mathrm{CO}_{2}$ compensation point $\left(\mu \mathrm{mol} \mathrm{mol}{ }^{-1}\right) . G_{\mathrm{c}}$ is then passed on to CN-CLASS to be used in an iterative solution of canopy temperature, $\mathrm{CO}_{2}$ concentration within stomata and $D_{\mathrm{s}}$. Thus, in the coupled $\mathrm{CN}$ version of the model $(\mathrm{CN}-$ CLASS), the soil-plant $\mathrm{N}$ cycle affects or regulates $G_{\mathrm{c}}$ and $A_{\text {net }}$ through the nonlinear relationship of $V_{\text {cmax }}$ to Rubisco-N.

The second key component of the CN-CLASS model is the C release module, which calculates autotrophic respiration from four living vegetation pools (nonstructural reservoir, leaf, stem and root), and heterotrophic respiration from three dead $\mathrm{C}$ pools, (i.e. litter, short-lived soil organic matter (SOM; analogue to soil microbial biomass and other labile SOM) and stable SOM (Arain et al., 2006). Generally, C releases are linearly related to individual pool sizes (C stocks) and adjusted by a temperature function, based on a $Q_{10}$ formulation. Heterotrophic respiration is also modified by substrate moisture content.

CN-CLASS also includes a simple $\mathrm{C}$ budget module that allocates the $C$ sequestered to four living vegetation pools, estimates litter-fall and decomposition and calculates SOM transformation. To accommodate all seven forests, which have a wide range of tree sizes and stem densities, within the model, a simple tree allometry module with dynamic leaf phenology was developed and incorporated in CN-CLASS. In this module, an 'expolinear' function for potential leaf growth and expansion based on thermal formulations (growing degree-days) was used to determine seasonal leaf area index $(L)$ following Ishag \& Dennett (1998):

$$
L=\frac{1}{k} \ln \left[\frac{1+\exp \left\{\operatorname{RGR}_{\mathrm{m}}\left(t-t_{\mathrm{b}}\right)\right\}}{1+\exp \left\{\operatorname{RGR}_{\mathrm{m}}\left(t-t_{\mathrm{b}}\right)-k \times L_{\max }\right\}}\right],
$$

where $k$ is the light extinction coefficient $(0.50), \mathrm{RGR}_{\mathrm{m}}$ is the maximum leaf relative growth rate $\left(0.015\right.$ degree-day $\left.^{-1}\right), t$ is growing degree-days, $t_{\mathrm{b}}$ is the accumulated growing degreedays at which leaf expansion reaches a linear phase, and $L_{\max }$ is the maximum $L$ which is a function of diameter at breast height $\left(d_{\mathrm{bh}}\right)$, following the pipe theory, which suggests that water transport in trees occurs almost exclusively in sapwood from roots to leaves so that maximum leaf area is linearly correlated with sapwood area (Turner et al., 2000):

$$
L_{\max }=l_{\mathrm{a}} \times A_{\mathrm{sw}},
$$

where, $l_{\mathrm{a}}$ is the ratio of $L$ to cross-sectional area of sapwood $\left(A_{\mathrm{sw}}\right)$ at breast height, which is often estimated from $d_{\mathrm{bh}}$ (Turner et al., 2000; Litton et al., 2003):

$$
A_{\mathrm{sw}}=\pi\left(\frac{0.89 \times d_{\mathrm{bh}}}{2}\right)^{2}-\pi\left(\frac{0.89 \times d_{\mathrm{bh}}}{2}-W_{\mathrm{sw}}\right)^{2},
$$

Here, 0.89 is a factor used to adjust $d_{\mathrm{bh}}$ to account for the inside-bark portion of $d_{\mathrm{bh}}(\mathrm{cm})$ and $W_{\mathrm{sw}}$ is the width of sapwood, calculated as:

$$
W_{\mathrm{sw}}=5.43\left[1-\exp \left(-0.046 d_{\mathrm{bh}}\right)\right],
$$

where 5.43 and -0.046 are two empirical constants for Douglas-fir. In this study they are assumed to be valid for other conifer sites as well.

The net assimilation, after subtracting autotrophic respiration and leaf mass increment, is allocated to stem and root pools by the prescribed allocation ratios depending upon plant functional type. Tree stems are divided into sapwood and heartwood, and roots are classified into coarse and fine roots. These can be estimated from $d_{\mathrm{bh}}$ as well (Gower et al., 1997; Turner et al., 2000; Litton et al., 2003):

$$
\begin{gathered}
\log \left(\frac{V_{\mathrm{sw}}}{P_{\mathrm{dty}}}\right)=a_{s}+b_{s} \times \log \left(d_{\mathrm{bh}}\right)+c_{s} \times d_{\mathrm{bh}} \\
\log \left(\frac{C_{\mathrm{crt}}}{P_{\mathrm{dty}}}\right)=2.50 \times a_{r}+b_{r} \times \log \left(d_{\mathrm{bh}}\right),
\end{gathered}
$$

where, $V_{\mathrm{sw}}$ is sapwood volume $\left(\mathrm{m}^{3} \mathrm{~m}^{-2}\right), C_{\mathrm{crt}}$ is the $\mathrm{C}$ in coarse root biomass $\left(\mathrm{kgCm}^{-2}\right), a_{\mathrm{s}}, b_{\mathrm{s}}, a_{\mathrm{r}}, b_{\mathrm{r}}, a_{\mathrm{w}}$ and $b_{\mathrm{w}}$ are the empirical constants, and $P_{\text {dty }}$ is the plant density (stems $\mathrm{m}^{-2}$ ). The value of 2.50 in Eqn (A10) has been added to the original equations of Litton et al. (2003) to convert from dry matter to C and to use $d_{\mathrm{bh}}$ instead of basal diameter as the independent variable. The biomass $C$ in fine roots $\left(C_{\mathrm{frt}}, \mathrm{kg} \mathrm{Cm}^{-2}\right)$ is calculated as the difference between coarse root biomass and total root biomass.

The $d_{\mathrm{bh}}$ (cm per tree) in Eqns (A6)-(A9) for trees can be determined from the stem biomass $\mathrm{C}\left(C_{\text {stem }}, \mathrm{kg} \mathrm{C} \mathrm{m}^{-2}\right)$, from a simple allometric relationship (Gower et al., 1997), if plant density $P_{\text {dty }}$ is known, i.e.

$$
\log \left(d_{\mathrm{bh}}\right)=\frac{-a_{w}}{b_{w}} \times \log \left(\frac{C_{\mathrm{stem}}}{P_{\mathrm{dty}}}\right) .
$$

Aboveground tree biomass (mainly stem biomass) indirectly constrains maximum $L$ [ $L_{\max }$ in Eqn (A5)] via its influence on $d_{\mathrm{bh}}$. Through the addition of a leaf growth function and vegetation allometry, the updated CN-CLASS now simulates vegetation dynamics. The soil-plant $\mathrm{N}$ algorithms in the CN-CLASS model mostly follow procedures in Dickinson et al. (2002) and Arain et al. (2006). 